\title{
Analysis of Parvocellular and Magnocellular Visual Pathways in Human Retina
}

\author{
Rania A. Masri, ${ }^{1,2}$ Ulrike Grünert, ${ }^{1,2}$ and Paul R. Martin ${ }^{1,2}$ \\ ${ }^{1}$ Faculty of Medicine and Health, Save Sight Institute and Discipline of Clinical Ophthalmology, The University of Sydney, Sydney, New South \\ Wales 2000, Australia, and ${ }^{2}$ Australian Research Council Center of Excellence for Integrative Brain Function, The University of Sydney, Sydney, \\ New South Wales 2000, Australia
}

Two main subcortical pathways serving conscious visual perception are the midget-parvocellular (P), and the parasol-magnocellular (M) pathways. It is generally accepted that the $\mathrm{P}$ pathway serves red-green color vision, but the relative contribution of $\mathrm{P}$ and $\mathrm{M}$ pathways to spatial vision is a long-standing and unresolved issue. Here, we mapped the spatial sampling properties of $\mathrm{P}$ and $\mathrm{M}$ pathways across the human retina. Data were obtained from immunolabeled vertical sections of six postmortem male and female human donor retinas and imaged using high-resolution microscopy. Cone photoreceptors, OFF-midget bipolar cells (P pathway), OFF-diffuse bipolar (DB) types DB3a and DB3b (M pathway), and ganglion cells were counted along the temporal horizontal meridian, taking foveal spatial distortions (postreceptoral displacements) into account. We found that the density of OFF-midget bipolar and OFF-midget ganglion cells can support one-to-one connections to 1.05-mm $\left(3.6^{\circ}\right)$ eccentricity. One-to-one connections of cones to OFF-midget bipolar cells are present to at least $10-\mathrm{mm}\left(35^{\circ}\right)$ eccentricity. The OFF-midget ganglion cell array acuity is well-matched to photopic spatial acuity measures throughout the central $35^{\circ}$, but the OFF-parasol array acuity is well below photopic spatial acuity, supporting the view that the $\mathrm{P}$ pathway underlies high-acuity spatial vision. Outside the fovea, array acuity of both OFF-midget and OFF-DB cells exceeds psychophysical measures of photopic spatial acuity. We conclude that parasol and midget pathway bipolar cells deliver high-acuity spatial signals to the inner plexiform layer, but outside the fovea, this spatial resolution is lost at the level of ganglion cells.

Key words: human vision; magnocellular; parvocellular; primate retina; spatial acuity; subcortical visual pathways

\section{Significance Statement}

We make accurate maps of the spatial density and distribution of neurons in the human retina to aid in understanding human spatial vision, interpretation of diagnostic tests, and the implementation of therapies for retinal diseases. Here, we map neurons involved with the midget-parvocellular ( $\mathrm{P}$ pathway) and parasol-magnocellular ( $\mathrm{M}$ pathway) through human retina. We find that P-type bipolar cells outnumber M-type bipolar cells at all eccentricities. We show that cone photoreceptors and P-type pathway bipolar cells are tightly connected throughout the retina, but that spatial resolution is lost at the level of the ganglion cells. Overall, the results support the view that the $\mathrm{P}$ pathway is specialized to serve both high acuity vision and redgreen color vision.

\footnotetext{
Received June 30, 2020; revised Aug. 26, 2020; accepted Sep. 22, 2020.

Author contributions: R.A.M., U.G., and P.R.M. designed research; R.A.M. performed research; R.A.M., U.G., and P.R.M. analyzed data; U.G. and P.R.M. wrote the paper.

This work was supported by the National Health and Medical Research Council Project Grant 1123418 (to U.G. and P.R.M.), a Fellowship of the Sydney Medical School Foundation (U.G.), a Research Training Program Scholarship of the Australian Government (R.A.M.), and an Ophthalmology and Vision Science PhD Scholarship by Save Sight Institute (R.A.M.). We thank the Lions NSW Eye Bank at Sydney Eye Hospital for making human donor eyes available. We also thank Arzu Demir, Sammy Lee and Siva Purushothuman for assistance with experiments, and Larry Thibos for helpful comments on the manuscript.

The authors declare no competing financial interests.

Correspondence should be addressed to Paul R. Martin at prmartin@sydney.edu.au.

https://doi.org/10.1523/JNEUROSCI.1671-20.2020

Copyright $\odot 2020$ the authors
}

\section{Introduction}

Neurons in the retina are organized into parallel pathways that convey signals serving distinct submodalities of vision (Wässle, 2004). Knowledge of the morphology and spatial distribution of retinal cells involved in specific pathways is pivotal to understanding how the visual scene is processed, and more broadly in relating the underlying precision of neural wiring to human visual performance.

It is customary to describe the midget-parvocellular $(\mathrm{P})$ pathway in diurnal primates as serving high acuity achromatic vision and red/green color vision (Nassi and Callaway, 2009; Lee et al., 2010), whereas the parasol-magnocellular (M) pathway is primarily involved in motion detection (Kaplan and Shapley, 1986; Croner and Kaplan, 1995; Crook et al., 2008). This view is 
however not universally accepted, because several features of $\mathrm{P}$ cell receptive fields (for example, low contrast sensitivity) are inconsistent with properties of human spatial vision (for review, see Shapley and Perry, 1986; Lee et al., 2010). The broad aim of the present study is to measure spatial sampling properties of bipolar cell arrays serving $\mathrm{P}$ and $\mathrm{M}$ pathways in human retina and judge their suitability as substrates for human form and color vision. We concentrate here on OFF-bipolar arrays because well-characterized antibodies to label OFF-P and OFF-M bipolar cells are available.

The resolution capacity of the $\mathrm{P}$ pathway in the fovea is set by the one-to-one convergence and tight synaptic connectivity between cones, midget bipolar, and midget ganglion cells. Studies in macaque and human retina showed over $80 \%$ of bipolar input to midget ganglion cells derives from midget bipolar cells (Kolb and DeKorver, 1991; Calkins et al., 1994; Tsukamoto and Omi, 2015). In macaques, the one-to-one ratio between cones and midget bipolar cells extends to at least $8-\mathrm{mm}\left(40^{\circ}\right) \mathrm{ec}-$ centricity (Wässle et al., 1994), but it is not known whether the same pattern of connections is present in human retina. This is an important question because an array of single-cone contacting midget bipolar cells can deliver both spatial and chromatic selective signals to the inner plexiform layer, and support chromatic selective responses in midget ganglion cells in peripheral retina (Martin et al., 2001; Reid and Shapley, 2002; Kolb and Marshak, 2003; Buzás et al., 2006; Wool et al., 2018).

There is evidence that the $\mathrm{M}$ pathway is involved in spatial vision at low image contrast, because individual parasol ganglion cells have threshold spatial acuity as high as that of individual midget ganglion cells (Kaplan and Shapley, 1986; Crook et al., 1988, 2008; Merigan et al., 1991; Croner and Kaplan, 1995). Parasol ganglion cells receive cone input via diffuse bipolar (DB) cells which contact multiple cone photoreceptors (Boycott and Wässle, 1991). Studies in macaque and marmoset retinas showed that the major bipolar input to OFF-parasol cells derives from DB3a, with lesser input from DB2 and DB3b cells (Jacoby and Marshak, 2000; Jacoby et al., 2000; Tsukamoto and Omi, 2015; Masri et al., 2016), whereas the input to ON-parasol ganglion cells derives mainly from DB4 and DB5 cells (Puthussery et al., 2013; Tsukamoto and Omi, 2016). The spatial density of these bipolar cell arrays sets an upper bound to spatial resolution capacity of the M pathway, but only one population (DB4 cells) has been analyzed quantitatively in macaque retina and no data are available for human retina (Grünert and Martin, 2020). Here, we measured spatial density of DB3a and DB3b cells in human retina to establish the distribution of $\mathrm{DB}$ cells contributing to the OFF-M pathway.

In the fovea, ganglion cells are displaced from the position of the cones that feed the receptive field center (Sjöstrand et al., 1999; Drasdo et al., 2007; Bringmann et al., 2018). Here, we measured lateral displacements in the same preparations as used to determine the densities of cones, bipolar and ganglion cells, enabling accurate calculation of the spatial resolving power of bipolar cells feeding $\mathrm{P}$ and $\mathrm{M}$ pathways in the human fovea.

\section{Materials and Methods}

Tissue collection and preparation

Postmortem human eyes from male and female donors with no known history of eye disease were obtained from the Lions NSW Eye Bank (Sydney Eye Hospital) and Australian Ocular Biobank with consent and ethical approval from The University of Sydney Human Research Ethics Committee (HREC \#2012/2833). Information about the donor eyes is summarized in Table 1. Four of the retinas used in this study were also
Table 1. Details of donor retinas

\begin{tabular}{lllllll}
\hline ID & Eye & Sex & Age (years) & $\begin{array}{l}\text { Time to } \\
\text { enucleation (h) }\end{array}$ & $\begin{array}{l}\text { Time to } \\
\text { fixation (h) }\end{array}$ & $\begin{array}{l}\text { Time in } \\
\text { fixative*(h) }\end{array}$ \\
\hline 13587 & Right & F & 44 & 2 & 4 & 12 \\
13699 & Right & M & 56 & 2 & 9 & 21 \\
14064 & Right & F & 44 & 1 & 3 & 13 \\
14458 & Left & F & 31 & 3 & 5 & 25 \\
$15415^{* *}$ & Left & F & 54 & 3 & 5 & 17 \\
15649 & Left & F & 36 & 0.5 & 8 & 40 \\
\hline
\end{tabular}

*All retinas were fixed in $2 \%$ PFA in $0.1 \mathrm{M} \mathrm{PB}$ while attached to the ora serrata and the retinal pigment epithelium. ${ }^{* *}$ The eye was placed into $\mathrm{CO}_{2}$ independent medium for $1 \mathrm{~h}$ before fixation. The cornea was removed but the anterior chamber for this eye was otherwise intact. Times above $1 \mathrm{~h}$ are shown to the nearest hour.

used in our previous study on the rod pathway in human retina (Lee et al., 2019). Retinas from donors under 60 years of age with a postmortem delay shorter than $10 \mathrm{~h}$ from death to fixation were used. Eyes were received with the cornea removed, and in most cases, the posterior eye cup was immersed in $2 \%$ paraformaldehyde (PFA) in $0.1 \mathrm{~m}$ phosphate buffer (PB). In one case (\#15415), eyes were first placed into $\mathrm{CO}_{2}$ independent medium (Invitrogen) for $1 \mathrm{~h}$ and subsequently fixed in $2 \% \mathrm{PFA}$ in $0.1 \mathrm{M} \mathrm{PB}$. Eyes were rinsed in $0.1 \mathrm{M} \mathrm{PB}$, and the retina was dissected out of the eye cup. The vitreous was removed and relieving cuts were made to flatten the retina. Retina quadrants were immersed in 30\% sucrose in $0.1 \mathrm{M} \mathrm{PB}$ overnight, then frozen in liquid nitrogen, and stored at $-80^{\circ} \mathrm{C}$ until use. Retinal pieces measuring $3-5 \mathrm{~mm}$ in width and $4-5$ $\mathrm{mm}$ in length were prepared from defined eccentricities along the nasaltemporal axis ( $1 \mathrm{~mm}$ nasal to $15 \mathrm{~mm}$ temporal). The retinal pieces were embedded in 3\% low melting Agarose (Sea Plaque Agarose Lonza) dissolved in PBS and sectioned vertically at a thickness of $100 \mu \mathrm{m}$ using a Vibratome (VT 1200 S, Leica Microsystems). Sections were processed immediately or kept in $0.1 \mathrm{M} \mathrm{PB}$ containing $0.05 \% \mathrm{NaN}_{3}$ for up to four weeks until use.

\section{Immunohistochemistry}

Sections were preincubated in 5\% normal donkey serum (NDS; Jackson ImmunoResearch) and 0.5\% Triton X-100 (BDH Chemicals) in PBS for $1 \mathrm{~h}$ or overnight. The antibodies used in this study are summarized in Table 2. Antibodies against recoverin were used to identify OFF-midget bipolar cells (Milam et al., 1993), antibodies against calbindin were used to identify DB3a cells (Haverkamp et al., 2003), and antibodies against CD15 were used to identify DB3b cells (Haverkamp et al., 2003; Puthussery et al., 2013). Cones were labeled with antibodies against cone arrestin (Wikler et al., 1997; Zhang et al., 2003), short wavelength-sensitive cones (S-cones) with antibodies against S-opsin, and ganglion cells were labeled with antibodies against RNA-binding protein with multiple splicing (RBPMS; Rodriguez et al., 2014). Sections were incubated with primary antibodies diluted in PBS containing 0.5\% Triton X-100, 0.05\% $\mathrm{NaN}_{3}$, and 3\% NDS for 4-7 d. Secondary antibodies (made in donkey) coupled to Alexa 594, Alexa 488 or Alexa 647 (Jackson ImmunoResearch) were diluted in PBS containing 0.5\% Triton X-100 and 3\% NDS. The nuclear stain 4',6-diamidino-2-phenylindole dihydrochloride (DAPI; $10 \mu \mathrm{g}$ / ml; D9542, Sigma) was usually added to the secondary antibody diluent. Sections were incubated in secondary antibody for 14-24 h. Adhesive spacers (20-mm diameter, 0.12-mm depth; ThermoFisher Scientific) were fitted onto poly-lysine-coated microscope slides. The tissue was rinsed, mounted within the wells of the adhesive spacers, then coverslipped using Vectashield Mounting Medium (Vector Laboratories Inc.).

\section{Microscopy}

Images were obtained using a confocal scanning microscope (Zeiss LSM700) equipped with 405-, 408-, 555-, and 635-nm lasers. The entire vibratome section (at least $3 \mathrm{~mm}$ in length and up to $100-\mu \mathrm{m}$ thickness) was imaged in tiled stacks which were subsequently stitched using Zeiss ZEN Black software. Stacks of images were obtained using $20 \times$ air objective (Plan Apochromat no. 420650-9901) at a resolution of $2048 \times 2048$ or $1024 \times 1024$ pixels and a step size of $0.87-1 \mu \mathrm{m}$ for each optical section. At the fovea, we used a $40 \times$ water immersion objective (Plan 
Table 2. Antibodies used in the current study

\begin{tabular}{|c|c|c|c|c|}
\hline Antibody name [cell type] & Immunogen & Source, catalog number, RRID & Antibody type & Dilution \\
\hline Calbindin (CaBP) [DB3a] & $\begin{array}{l}\text { CaBP-D-28 kDa purified from chicken gut; hybridoma produced by the } \\
\text { fusion of mouse myeloma cells and splenocytes from an immunized } \\
\text { mouse }\end{array}$ & $\begin{array}{l}\text { Swant, 300, lot: 07(F); RRID: AB_ } \\
\quad 10000347\end{array}$ & Mouse monoclonal & $1: 10,000$ \\
\hline CD15 [DB3b] & $\begin{array}{l}\text { U-937 histiocytic cell line, purified from tissue culture supernatant or } \\
\text { ascites by affinity chromatography }\end{array}$ & $\begin{array}{l}\text { BD Biosciences, 559045; RRID: } \\
\text { AB_397181 }\end{array}$ & Mouse monoclonal & $1: 100$ \\
\hline Cone arrestin (7G6) [cones] & $\begin{array}{l}\text { Developed using macaque light-adapted retinal extract as immunogen; } \\
\text { gives single band of } 44-46 \mathrm{kDa} \text { on Western blottings of human retina }\end{array}$ & $\begin{array}{l}\text { Gift from Prof. Peter Macleish, Morehouse } \\
\text { School of Medicine, Atlanta, GA; RRID: } \\
\text { AB_2314215 }\end{array}$ & Mouse monoclonal & $1: 500$ \\
\hline Parvalbumin [ganglion cells] & Purified from carp muscles; stains the ${ }^{35} \mathrm{Ca}$-binding spot of parvalbumin & $\begin{array}{l}\text { Swant, 235, lot: 10-11 (F); RRID: } \\
\text { AB_10000343. }\end{array}$ & Mouse monoclonal & $1: 20,000$ \\
\hline RNA-RBPMS [ganglion cells] & $\begin{array}{l}\text { Synthetic peptide corresponding to amino acid residues from the } \mathrm{N} \text {-ter- } \\
\text { minal region of the rat RBPMS sequence, recognizes the } 24-\mathrm{kDa} \\
\text { RBPMS protein }\end{array}$ & $\begin{array}{l}\text { Lubio, PhosphoSolutions, 1832-RBPMS, } \\
\text { Iot: NB9160; RRID: AB_2492226 }\end{array}$ & Guinea pig polyclonal & $1: 500$ \\
\hline RNA-RBPMS [ganglion cells] & $\begin{array}{l}\text { Recombinant protein encompassing a sequence within the left region of } \\
\text { human RBPMS }\end{array}$ & $\begin{array}{l}\text { Gene Tex, Sapphire Bioscience, } \\
\text { GTX118619, lot: } 40415 \text { RRID: } \\
\text { AB_10720427 }\end{array}$ & Rabbit polyclonal & $1: 500$ \\
\hline S-Opsin [S-cones] & $\begin{array}{l}\text { Peptide corresponding to amino acids } 1-50 \text { from the } N \text { terminus of the } \\
\text { opsin protein encoded by OPN1SW of human origin }\end{array}$ & $\begin{array}{l}\text { Santa Cruz, sc-14363, lot: A2813; RRID: } \\
\quad \text { AB_2158332 }\end{array}$ & Goat polyclonal & $1: 100$ \\
\hline
\end{tabular}

Table 3. Best fit parameters for pooled data

\begin{tabular}{|c|c|c|c|c|c|c|}
\hline & $c_{1}$ & $\lambda_{1}$ & $\mathrm{C}_{2}$ & $\lambda_{2}$ & $C_{3}$ & $\lambda_{3}$ \\
\hline Cones & $3.673 e+05$ & $-7.828 \mathrm{e} 0$ & $-2 e+05$ & $-2.000 e+03$ & $2.034 \mathrm{e}+04$ & $-2.164 \mathrm{e}-01$ \\
\hline S-cones & $5.048 \mathrm{e}+03$ & $-3.014 \mathrm{e} 0$ & $-1.1 e+04$ & $-7.869 \mathrm{e} 0$ & $1.455 \mathrm{e}+03$ & $-1.370 \mathrm{e}-01$ \\
\hline Ganglion cells & $5.717 e+05$ & $-1.031 \mathrm{e} 0$ & $-6 e+05$ & $-1.261 \mathrm{e} 0$ & $-5.527 e+01$ & $-9.658 e+01$ \\
\hline DB3a cells & $4.275 \mathrm{e}+03$ & $-1.949 \mathrm{e}-01$ & $-9.614 e+03$ & $-5.831 \mathrm{e} 0$ & $3.336 \mathrm{e}+02$ & 5.811e-03 \\
\hline DB3b cells & $7.061 e+03$ & $-1.511 \mathrm{e}-01$ & $-7.869 \mathrm{e}+03$ & $-3.120 \mathrm{e} 0$ & $-3.653 e+03$ & $-3.347 e-01$ \\
\hline
\end{tabular}

Numbers show best fit parameters for sum-of-exponential fits. $c_{1}, c_{2}, c_{3}$, multiplicative coefficients. $\lambda_{2}, \lambda_{2}, \lambda_{3}$, exponential coefficients.

Apochromat no. 421767-9970) to obtain stacks of images to distinguish individual cones. Depth readings taken using the air objective were corrected to account for the refractive index of the Vectashield mounting medium (1.45). The contrast and brightness of the images were adjusted using Zen Blue (Zeiss), Adobe Photoshop, or Imaris (Bitplane) software.

\section{Experimental design and statistical analysis}

Individual OFF-midget bipolar and DB cells (DB3a and DB3b) were reconstructed from stacks of confocal images using the surface tool in Imaris. The diameter of the bipolar axon terminals was measured from reconstructed terminals at three different eccentricities.

The density of cells was determined from tiled stacks of images using Zeiss ZEN Blue software as described previously by Lee et al. (2019). Cells were counted from volumetric reconstructions of Vibratome sections. The length of the section was divided into bins of $100 \mu \mathrm{m}$ width, and cells were counted within each bin across a minimum depth of $10 \mu \mathrm{m}$ in the $z$-plane. Areal densities $\left(\right.$ cells $/ \mathrm{mm}^{2}$ ) were calculated for each bin using the formula $D=w \times d$, where $D$ is cell density, $w$ is the bin width, and $d$ is depth in the $z$-plane. Counts were made from between 9 and 21 sections for each antibody; a minimum of 20 cells was counted for each $100-\mu \mathrm{m}$ bin by adjusting the $z$-plane sample depth. As in our previous study (Lee et al., 2019), these values were chosen to give the best practical compromise between sample statistical power at each point (i.e., $\sim 5 \%$ sample noise at each point) and accurate estimates of cell density gradients (i.e., 10 density samples/linear $\mathrm{mm}$ ). For one preparation (case \#1357R; recoverin staining) density values were crosschecked against counts obtained from whole mount pieces flanking the vibratome section yielding consistent results.
Cells were counted when the morphology, stratification, and pattern of expression was consistent with previous descriptions: OFFmidget bipolar cells (Boycott and Wässle, 1991; Milam et al., 1993; Wässle et al., 1994; Kolb and Marshak, 2003); DB cells (Boycott and Wässle, 1991; Grünert et al., 1994; Jacoby et al., 2000; Tsukamoto and Omi, 2015). Ganglion cells were always counted in conjunction with the DAPI nuclear stain to identify the nucleus and thereby avoid counting the same cell in more than one optical plane. Vertical sections taken across the entire length and depth of the fovea were used to locate the foveal center where the foveal pit was deepest and the cone density was highest.

Eccentricity was calculated by taking into account the triangulated distance from the fovea. Average densities for each cell population were determined from samples at various eccentricities along the temporal horizontal meridian. No correction for shrinkage was applied because (1) the retina remained attached to the ora serrata and retinal pigment epithelium during fixation, (2) PFA fixation produces minimal shrinkage (Curcio and Allen, 1990; Abbott et al., 2009), and (3) the tissue was mounted using a water based mounting medium (Vectashield). Postreceptoral cell density as a function of eccentricity was fit in MATLAB V9.2 (MathWorks) with three-stage difference-of-exponentials functions, across eccentricities from 0 to $15 \mathrm{~mm}$ along the temporal horizontal axis. Because a limited number of foveal sections was available, our sample resolution at the foveal center is lower than that achieved in previous studies of cones and ganglion cells in human retina (Curcio and Allen, 1990; Curcio et al., 1990). Optimal fit parameters are given in Table 3 for the equation: $D=c_{1} \exp \left(\lambda_{1} X\right)+c_{2} \exp \left(\lambda_{2} X\right)+c_{3} \exp \left(\lambda_{3} X\right)$, where $D$ is cell density (cells/mm $\left.{ }^{2}\right), \lambda_{1}, \lambda_{2}$ and $\lambda_{3}$ are exponential coefficients, $c_{1}, c_{2}$ and $c_{3}$ are multiplicative coefficients, and $X$ is eccentricity $(\mathrm{mm})$. 

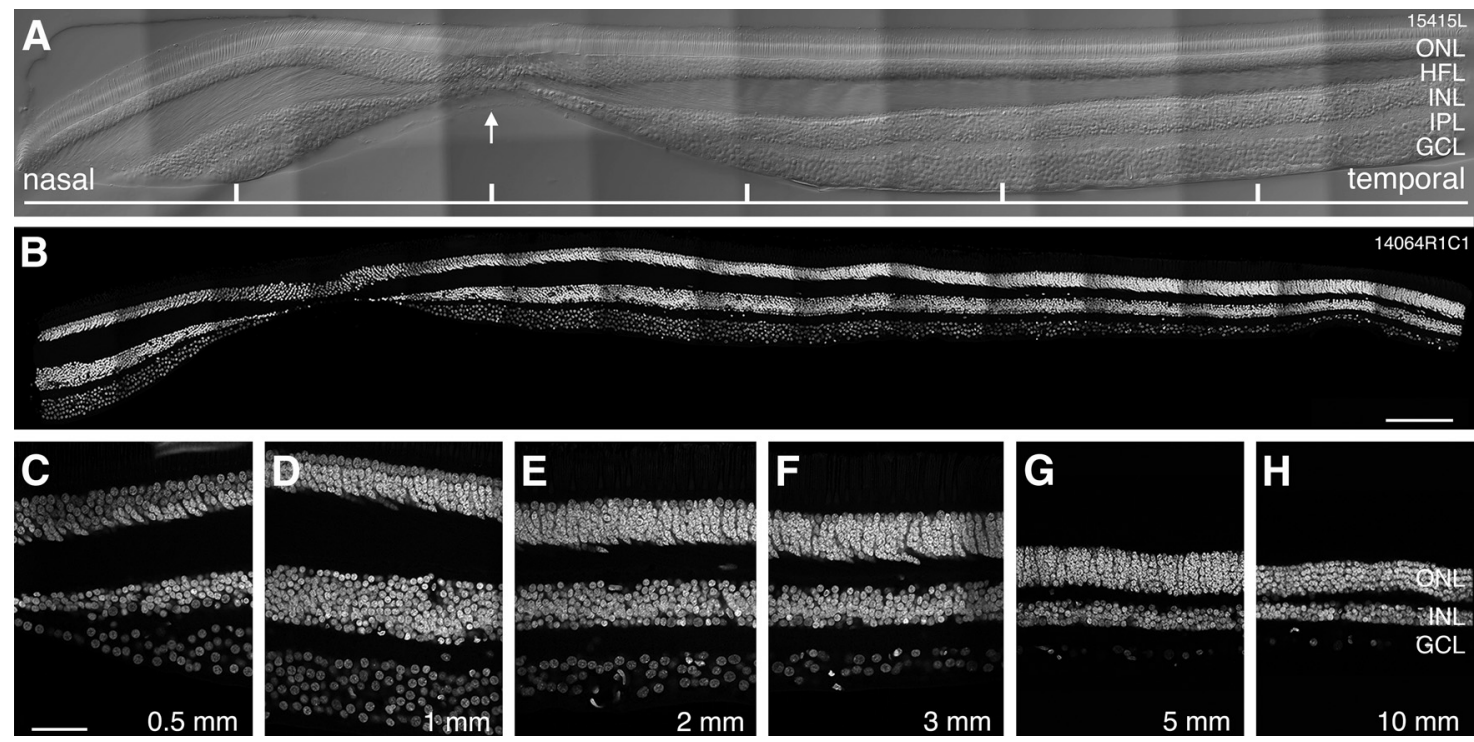

Figure 1. Retinal layers across the horizontal meridian. Confocal images of vertical sections through human retina cut through the fovea along the horizontal axis. $A$, Micrograph of a vertical section cut through the fovea of retina \#15415. Nomarski optics is used to reveal retinal layers, the arrow points to the foveal pit. Tick marks are $500 \mu \mathrm{m}$ apart. $\boldsymbol{B}$, Micrograph of a vertical section cut through the fovea of retina \#14064 showing DAPI nuclear stain. $\mathbf{C}-\boldsymbol{H}$, Regions of interest from retina \#14064 showing DAPI labeled nuclei at different eccentricities. The ganglion cell layer is six cells deep at 1-mm eccentricity and about one cell deep by 5-mm eccentricity. ONL: outer nuclear layer, INL: inner nuclear layer, GCL: ganglion cell layer. Scale bars: $200 \mu \mathrm{m}(\boldsymbol{B})$ and $50 \mu \mathrm{m}(\boldsymbol{C}$, applies to $\boldsymbol{C}-\boldsymbol{H})$.

Negative fit values in the fovea were set to zero. Cumulative density across the horizontal meridian was calculated by circular integration of spatial densities within annuli of defined eccentricity ranges, radiating from the foveal center in a "bullseye" pattern. The following formula was applied to calculate the number of cells within each annulus:

$$
\begin{aligned}
& \text { Density }\left(\frac{\text { cells }}{m^{2}}\right) \times \text { Annulus Area }\left(\mathrm{mm}^{2}\right) \\
& \text { Annulus Area }=\left(\pi \times r_{o}^{2}\right)-\left(\pi \times r_{i}^{2}\right),
\end{aligned}
$$

where $r_{o}$ represents the radius of the outer border and $r_{i}$ represents the radius of the inner border of the eccentricity range in question.

For comparison to human photopic acuity measurements, the maximum resolvable spatial frequency (Nyquist limit) of an hexagonal mosaic with spatial density $D$ was calculated for each measured cell population using the formula $N=m /(a \sqrt{3})$, where $N$ is the Nyquist limit (cycles per degree), $m$ is the retinal magnification factor, and $a$ is the intercell distance. Intercell distance was calculated as $a=\sqrt{1 /\left(\frac{\sqrt{3}}{2} D\right)}$, where $D$ is the population spatial density $\left(\right.$ cells $\left./ \mathrm{mm}^{2}\right)$. For simplicity, we ignored the nonlinear relation of retinal magnification to eccentricity (Drasdo and Fowler, 1974); we used a constant magnification factor of $0.29 \mathrm{~mm} /{ }^{\circ}$. This simplification introduces maximum $\sim 10 \%$ overestimate of retinal magnification at $30^{\circ}$; exact magnification values can be recovered by reference to Drasdo and Fowler (1974; their Figure 5).

\section{Receptoral and postreceptoral displacement}

Receptoral displacement (Henle fiber length) in temporal retina was determined using stacks of confocal images to trace the axons of individual cone photoreceptors to their synaptic terminal (cone pedicle). The horizontal distance between the cone pedicle and the soma was measured. Postreceptoral displacement was measured as the horizontal distance from the midline of the dendritic tree (presumed location of the cone pedicle) of the bipolar cell to the midline of the bipolar axon terminal.

\section{Terminology}

Based on previous studies (Hendrickson, 2005; Provis et al., 2013; Strettoi et al., 2018; Lee et al., 2019), we employ the following definitions: foveal retina refers to a radius of $0.8 \mathrm{~mm}$ ( $5.5^{\circ}$ diameter of visual angle), central retina refers to eccentricities up to $3.0 \mathrm{~mm}$ (first $10^{\circ}$ radius of visual angle) where the ganglion cell layer is more than one cell thick, roughly equivalent to the diameter of the macula lutea (Boycott et al., 1987; Bringmann et al., 2018), mid-peripheral retina refers to eccentricities between 3.0 and $6 \mathrm{~mm}$ and eccentricities beyond $6 \mathrm{~mm}$ are referred to as far peripheral retina.

\section{Results}

Data were obtained from one male and five female human donor retinas aged from 30 to 60 years (Table 1). Retinas were free from any obvious pathology, and the yellow pigment of the macula lutea was readily distinguishable (which facilitated identification of the fovea before sectioning). We did not specifically address the question of age-related differences in the distribution of retinal neurons but observed that variation between retinas was not obviously dependent on donor age. Figure 1 shows confocal images of vertical sections through the fovea of a 54-yearold (\#15415; Fig. 1A) and a 44-year-old (\#14604; Fig. $1 B-H$ ) female donor. The center of the fovea, where cone photoreceptor density is highest and the inner retinal layers are displaced, is indicated by the arrow in Figure $1 A$. The figure also shows that the thickness of the nuclear layers, and thus the cell density changes significantly with eccentricity.

Multiple immunohistochemical markers were applied to such sections to compare different populations of neurons in the same preparation. Each section was imaged across its entire length and Z-stack depth at high resolution. Regions where there was distortion of retinal layers or poor immunohistochemical staining were excluded from the cell counts.

\section{Cone photoreceptors}

As reported previously, cone arrestin is expressed in the entire cone including the outer and inner segments, the axon (Henle fiber) and the pedicles of all cone types (Wikler et al., 1997; Zhang et al., 2003). This pattern of expression is consistent across all eccentricities (Fig. $2 A-E$ ). Figure $2 A-E$ also shows that the 



H
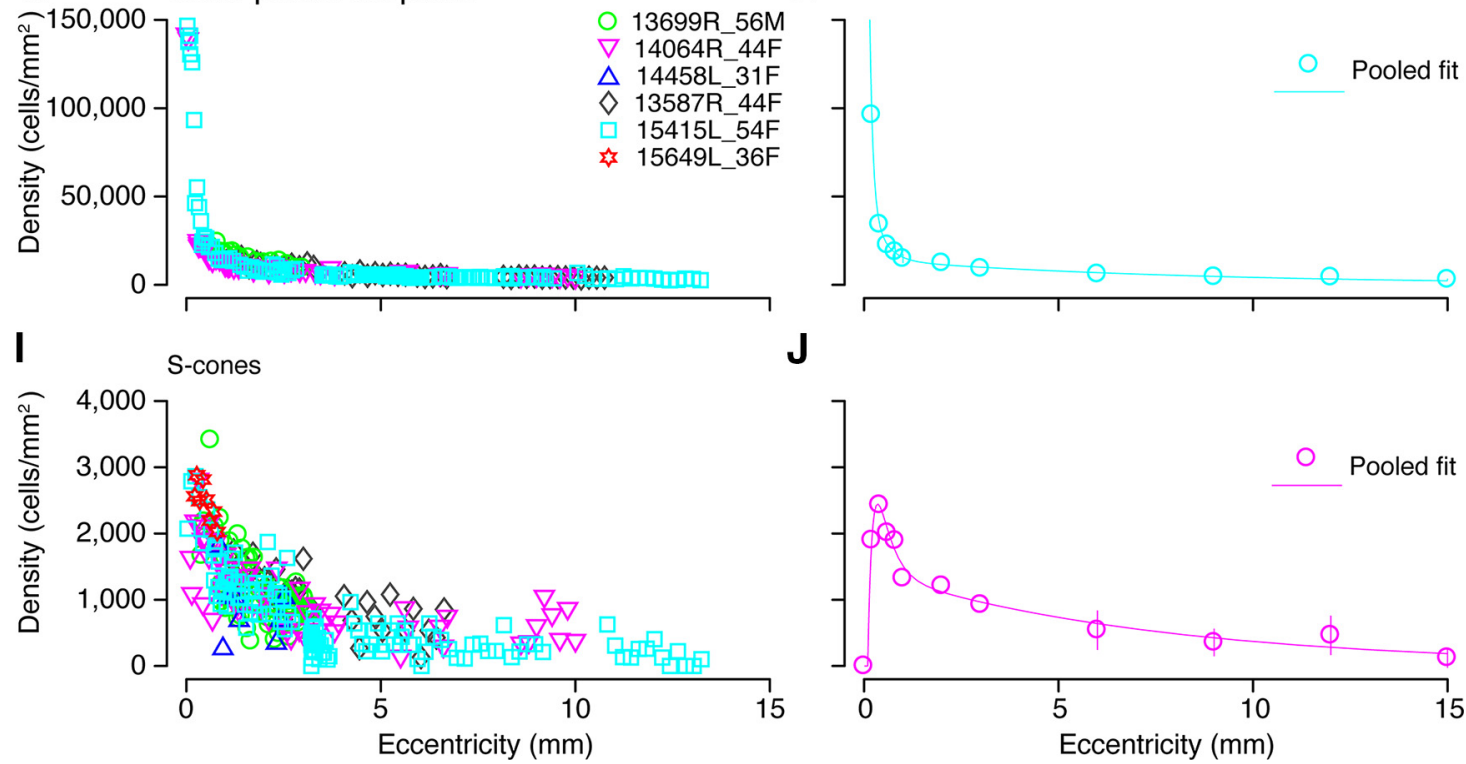

$\mathbf{J}$

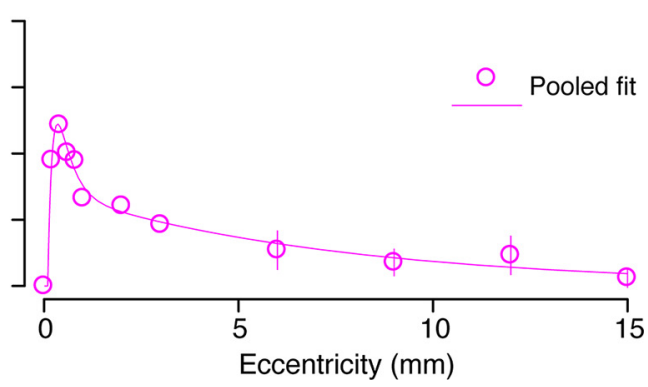

Figure 2. Cone photoreceptors: immunohistochemical labeling and spatial density. $\boldsymbol{A}-\boldsymbol{E}$, Confocal images of vertical vibratome sections through the fovea stained with antibodies against cone arrestin to reveal cone photoreceptors in preparation \#14064. Eccentricities are indicated in the upper right corners of the images. The diameter of the cone inner segments increases with eccentricity as cones become less tightly packed. The arrow in $\boldsymbol{E}$ points to the inner segment of a cone. $\boldsymbol{F}$, Confocal image of a vertical section through the fovea of preparation \#15415L showing $\mathrm{S}$-opsin expression. S-cones are near-absent at the fovea. The Henle fibers of the $\mathrm{S}$-cones can be observed. The inset in $\boldsymbol{F}$ shows a different focal plane of the same vibratome section. The region is $115 \mu \mathrm{m}$ wide and includes the $S$-cone-free zone at the foveal center. Total cone density $(\boldsymbol{G})$ and $S$-cone density $(\boldsymbol{I})$ are plotted against eccentricity from up to six preparations. Each preparation is allocated a unique symbol and each point on the graph represents the density ( $y$-axis) of the target cell type within a counting window at a particular eccentricity ( $x$-axis). Pooled data from the six preparations is fit to a curve shown in $\boldsymbol{H}$ for all cones and in $\boldsymbol{J}$ for $\mathrm{S}$-cones. Error bars (in many cases smaller than the marker symbols) show SDs. ONL: outer nuclear layer, HFL: Henle fiber layer, INL: inner nuclear layer, IPL: inner plexiform layer, GCL: ganglion cell layer. Scale bars: $50 \mu \mathrm{m}(\boldsymbol{E}$, applies to $\boldsymbol{A}-\boldsymbol{E})$ and $100 \mu \mathrm{m}(\boldsymbol{F})$.

diameter of the cone inner and outer segments increases with eccentricity whereas the cone density decreases.

Cone density was estimated in fourteen vibratome sections from four preparations stained for cone arrestin by counting the cone inner segments (Fig. 2E, arrow). In two sections from mid-peripheral and far peripheral retina (preparations \#13587 and \#15415), cone density was estimated from calbindin labeling. Calbindin is expressed by medium and long wavelength but not S-cone photoreceptors in human retina (Chiquet et al., 2002). Thus, these latter counts do not include S-cones.
Peak cone density at the foveal center was derived from two preparations which demonstrated comparable density $(150,667$ cells $/ \mathrm{mm}^{2}$ and 141,935 cells $/ \mathrm{mm}^{2}$; Fig. $\left.2 G, H\right)$. These values are lower than the average peak density of 199,000 cells $/ \mathrm{mm}^{2}$ reported by Curcio and colleagues, who measured density from whole mount preparations (Curcio et al., 1990), but our values lie within the range of individual variability in their study. The density of cones in the foveal center changes dramatically such that an error of $100 \mu \mathrm{m}$ could reduce the peak cone density by half (Packer et al., 1989), meaning that we may have underestimated peak foveal densities. Overall, the pattern of cone 

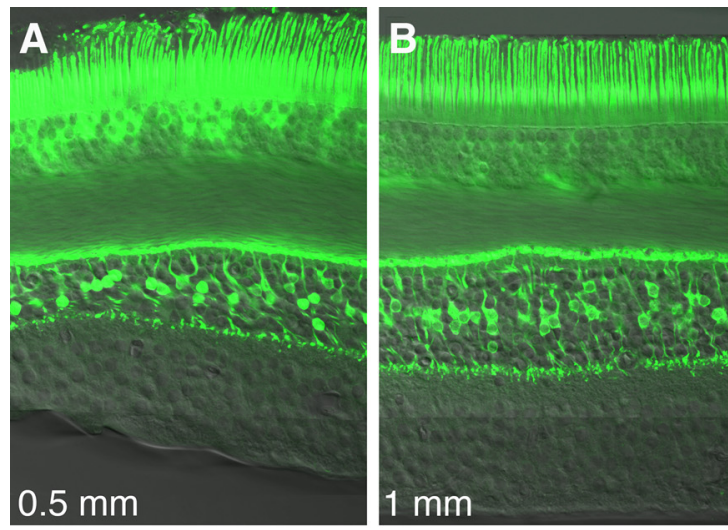

E

OFF midget bipolar cells





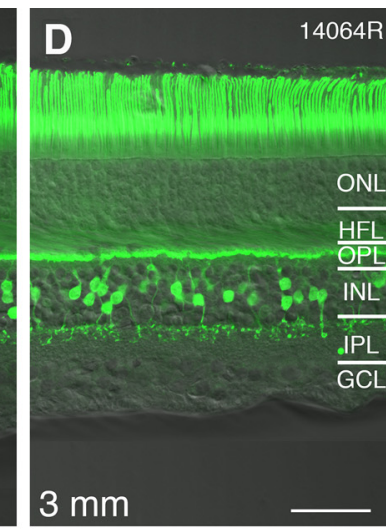

$\mathbf{F}$



Figure 3. OFF-midget bipolar cells: immunohistochemical labeling and spatial density. A-D, Confocal micrographs of a vertical section from preparation \#14064 stained with antibodies against recoverin to label OFF-midget bipolar cells. Recoverin immunoreactivity is shown in conjunction with Nomarski optics to reveal retinal layers. Expression of recoverin can be observed in the photoreceptors as well as OFF-midget bipolar cells. $\boldsymbol{E}$, Spatial density of OFF-midget bipolar cells is plotted against eccentricity for four preparations. $\boldsymbol{F}$, Pooled data from the four preparations in $\boldsymbol{E}$, fit to a curve to illustrate population density of OFF-midget bipolar cells across the retina. Error bars (in many cases smaller than the marker symbols) show SDs. ONL: outer nuclear layer, HFL: Henle fiber layer, OPL: outer plexiform layer, INL: inner nuclear layer, IPL: inner plexiform layer, GCL: ganglion cell layer. Scale bar: $50 \mu \mathrm{m}(\boldsymbol{D}$, applies to $\boldsymbol{A}-\boldsymbol{D})$.

distribution across the retina is consistent with previous reports (Østerberg, 1935; Curcio et al., 1990; Sjöstrand et al., 1999): cone density declines steeply outside the fovea, falling to an average of 15,000 cells $/ \mathrm{mm}^{2}$ by $1-\mathrm{mm}$ eccentricity. The cone density continues to decline gradually in mid-peripheral retina and drops to $\sim 3500$ cells $/ \mathrm{mm}^{2}$ beyond $12-\mathrm{mm}$ eccentricity (Fig. 2 G,H).

The S-cones were identified with an antibody against S-opsin (Fig. 2F). As expected, S-cones are sparse in the fovea and absent at the foveola (Curcio et al., 1991). The S-cones were counted at the level of their inner segments (\#13587, \#13699, \#14064) or their somas (\#15415 and \#15649). The S-cone density was estimated in six preparations from 20 sections, two of which included the foveal center (Fig. 2I). Consistent with previous reports (Curcio et al., 1991), average S-cone density peaks at $0.36-\mathrm{mm}$ eccentricity temporal with a density of 2400 cells $/ \mathrm{mm}^{2}$ (range 2100-2880 cells $/ \mathrm{mm}^{2}$; Fig. 2J). The location of the peak varied slightly between preparations, ranging from 0.23 - to 0.32 $\mathrm{mm}$ eccentricity. The S-cone free zone was measured across the temporal axis in one preparation (\#15415): it had a diameter of $70 \mu \mathrm{m}$, with the first S-cones appearing as close as $30-\mu \mathrm{m}$ eccentricity in temporal retina (Fig. $2 F$, inset). The proportion of S-cones was determined from the pooled data shown in Figure $2 H$,J. The Scones made up $6 \%$ of the cone population at their average peak density, and this proportion gradually increased to $\sim 8-10 \%$ beyond $1-\mathrm{mm}$ eccentricity. These findings are consistent with previous reports in human (Curcio et al., 1991) and non-human primates (Marc and Sperling, 1977; Wikler and Rakic, 1990; Martin and Grünert, 1999). Taken together, our results show that the density of cone photoreceptors can be quantified using immunolabeled vertical sections through the retina, but some accuracy may be sacrificed in estimates of peak cone density.

\section{Off-midget bipolar cells}

Consistent with previous findings in human retina (Milam et al., 1993; Haverkamp et al., 2003) recoverin is expressed by rod and cone photoreceptors and also by large numbers of bipolar cells with cell bodies in the center of the inner nuclear layer (Figs. 3A$D, 4 B)$. Recoverin immunoreactivity is present in the primary dendrite, the soma, and the axon terminal of the bipolar cells. The broadly stratifying axonal terminals are located in the outer half of the inner plexiform layer. This morphology is consistent with descriptions of OFF-midget bipolar cells (Kolb et al., 1992; Milam et al., 1993; Wässle et al., 1994). We note that Milam et al. (1993) suggest that recoverin is expressed by another bipolar cell type which is present at very low densities. We could not isolate an additional recoverin positive bipolar cell, but if this population is present its inclusion would result in only a slight overestimation of OFF-midget bipolar cell density.

In total 17 vibratome sections from four retinal preparations processed with antibodies against recoverin were analyzed; four sections included the fovea. In one preparation (\#15649), some recoverin-labeled somas were also encountered near the border with the inner plexiform layer (data not shown). These cells did not show the typical bipolar morphology and thus were presumed to be amacrine cells and excluded from the counts. In preparation \#15415 recoverin immunoreactivity was present in photoreceptors but near absent in bipolar cells, although the expression of other immunohistochemical markers was normal in this preparation (e.g. Fig. 2F). This preparation was not included in the density counts for midget bipolar cells.

Figure $3 E, F$ shows the spatial density of recoverin labeled OFF-midget bipolar cells in four preparations. The greatest variation in density between preparations is between 0.5 - and 1.5- 

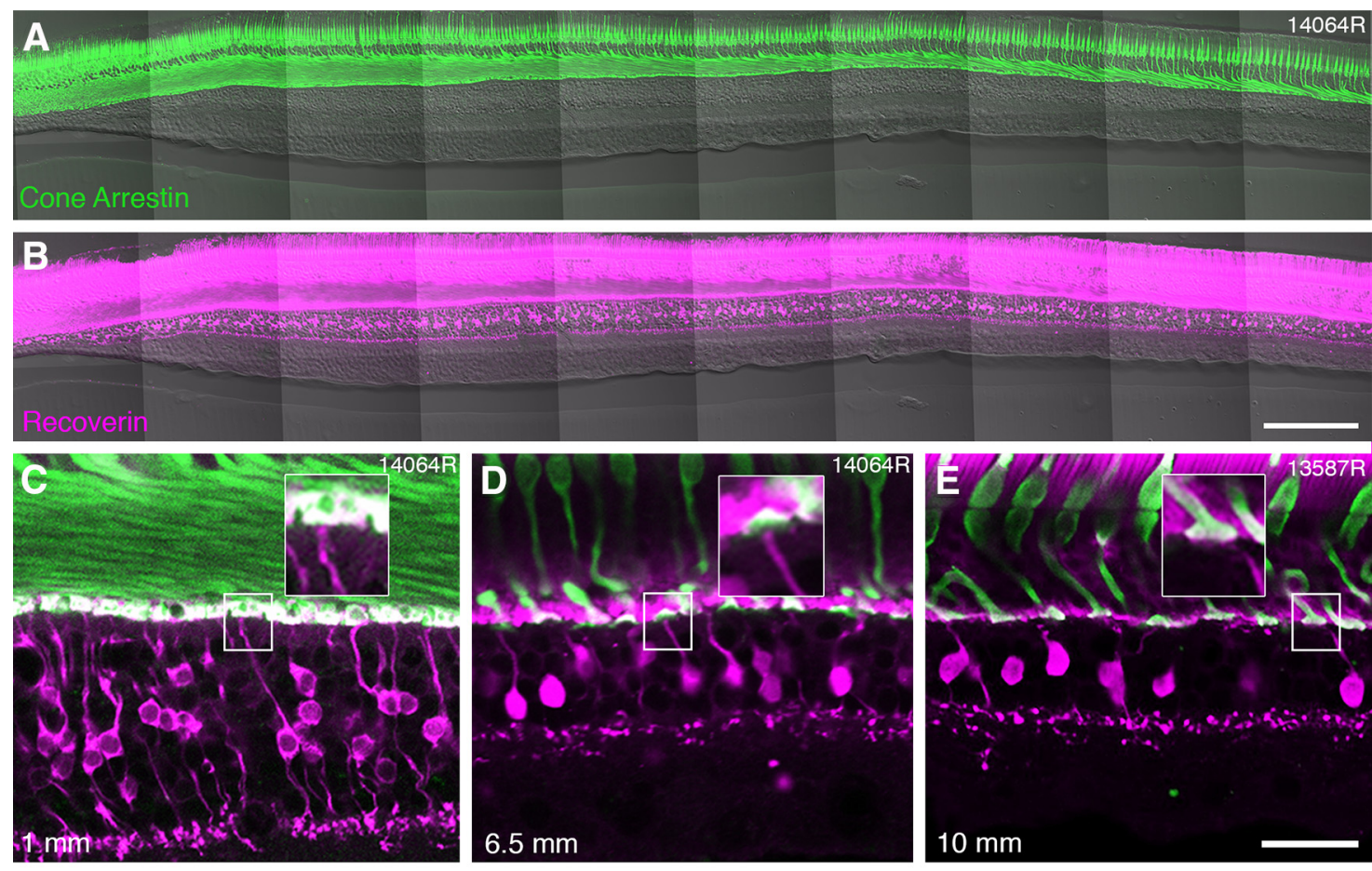

$\mathbf{F}$

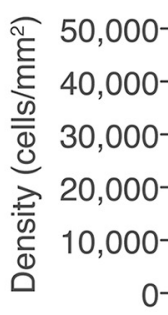

13587R 44F $\diamond$ Cone photoreceptors =OFF midget bipolar cells

G

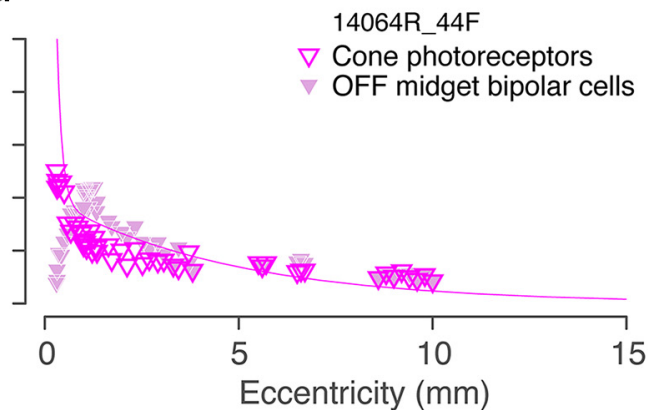

Figure 4. Convergence of cones to midget bipolar cells. $A, B$, Confocal images of a vertical vibratome section through temporal retina $300 \mu m$ superior to the fovea of preparation \#14064 stained with antibodies against cone arrestin $(\boldsymbol{A})$ and recoverin $(\boldsymbol{B})$. $\boldsymbol{C}-\boldsymbol{E}$, Confocal images from sections double labeled for cone arrestin and recoverin to illustrate connectivity between cone photoreceptors and OFF-midget bipolar cells at various eccentricities. Insets in each image show that single-headed flat midget bipolar cells can be identified up to at least 10-mm eccentricity. Eccentricity is indicated in the lower left corner. $\boldsymbol{F}, \mathbf{G}$, Cell density is plotted against eccentricity for cone photoreceptors and flat midget bipolar cells in preparation \#13587 (F) and \#14064 (G). Open circle symbols in panel $\boldsymbol{F}$ show values obtained from whole mounts, as described in the text. The curves represent the average density of cone photoreceptors across all preparations. In both preparations, the ratio of cones to OFF-midget bipolar cells is 1:1 in peripheral retina. Scale bars: $200 \mu \mathrm{m}(\boldsymbol{B}$, applies to $\boldsymbol{A}, \boldsymbol{B})$ and $50 \mu \mathrm{m}(\boldsymbol{E}$, applies to $\boldsymbol{C}-\boldsymbol{E})$.

mm eccentricity (Fig. 3E). The density of OFF-midget bipolar cells peaks near $1 \mathrm{~mm}$ at an average of 22,000 cells $/ \mathrm{mm}^{2}$ (range 19,70031,800 cells $/ \mathrm{mm}^{2}$; Fig. $3 F$ ). The pooled fit shows the density of OFF-midget bipolar cells decreases rapidly between 1 and $4 \mathrm{~mm}$, and then gradually declines to 6300 cells $/ \mathrm{mm}^{2}$ by $9-\mathrm{mm}$ eccentricity. There was no obvious variation in the distribution of OFF midget bipolar cells between temporal and nasal retina within 1 $\mathrm{mm}$ from the fovea. Peripheral nasal retina was not studied.

In one preparation (case \#13587R) we compared the areal density calculated for recoverin-labeled cells with density measured from two flat mount pieces flanking the vibratome sections in peripheral retina (Fig. $4 F$, open circles). The whole mount counts yielded only marginally lower density estimates (mean \pm SD, 4184 $\pm 545, n=8)$ than did the vibratome section counts (5143 \pm 938 ; $n=14 ; p=0.02$, Wilcoxon non-parametric rank-sum test for independent samples), indicating there is no large systematic bias in estimates of areal density from vertical sections.

We analyzed vibratome sections double labeled for cone arrestin (Fig. 4A) and recoverin (Fig. 4B) and found abundant examples of OFF-midget bipolar dendrites contacting single cone pedicles in central (Fig. 4C), mid-peripheral (Fig. 4D), and far peripheral (Fig. $4 E$ ) retina. We did not see clear examples of branched midget bipolar dendrites at eccentricities below $8 \mathrm{~mm}$, but we did observe occasional examples of midget bipolar cells contacting multiple cones at eccentricities between 8 and $10 \mathrm{~mm}$ (Fig. 5C).

We used double-labeled sections to directly compare the spatial density of cone photoreceptors and OFF-midget bipolar cells within the same preparation (\#13587 and \#14064). In both preparations the ratio of cones to OFF-midget bipolar cells is close to 1:1 up to at least 10 -mm eccentricity (Figs. $4 F, G$ ). Taken together, the matched spatial densities and abundance of singlecone contacting OFF-midget bipolar cells implies predominantly one-to-one connectivity between these two populations at least to 10 - $\mathrm{mm}\left(\sim 35^{\circ}\right)$ eccentricity. Kolb et al. (1992) obtained consistent results from Golgi impregnated human retina and also showed examples of single-cone contacting invaginating (ON) midget bipolar cells up to 8 -mm eccentricity their Fig. 26C, suggesting that low cone convergence may also be a feature of the $\mathrm{ON}$-midget system in human retina. 

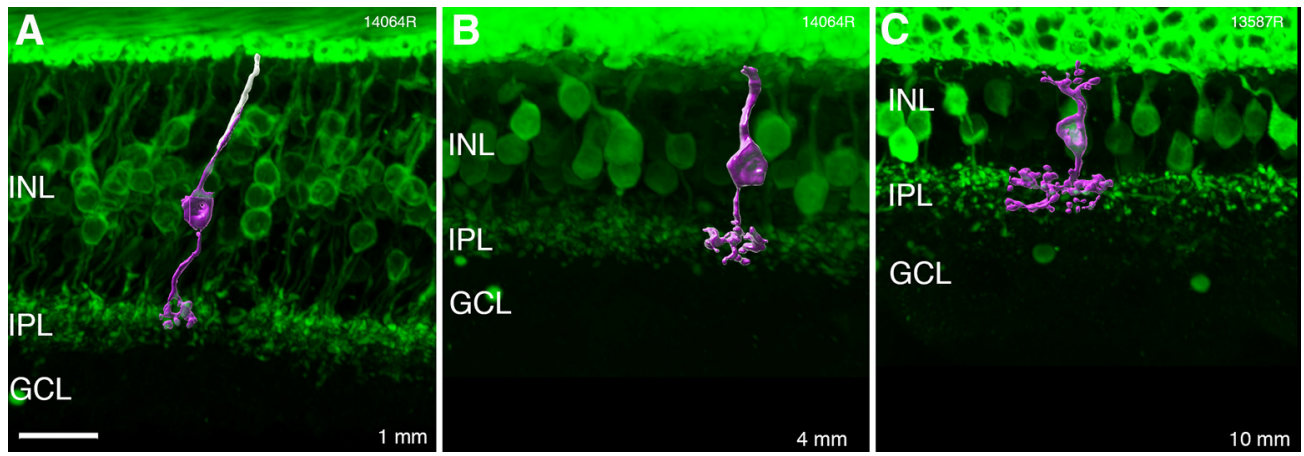

Figure 5. Reconstructions of OFF-midget bipolar cells. $A-C$, Confocal images and three-dimensional reconstructions of OFF-midget bipolar cells from recoverin-labeled vertical sections taken at three different eccentricities (indicated in the lower right corner). INL: inner nuclear layer, IPL: inner plexiform layer, GCL: ganglion cell layer. Scale bar: $20 \mu \mathrm{m}$ ( $\boldsymbol{A}$, applies to all).
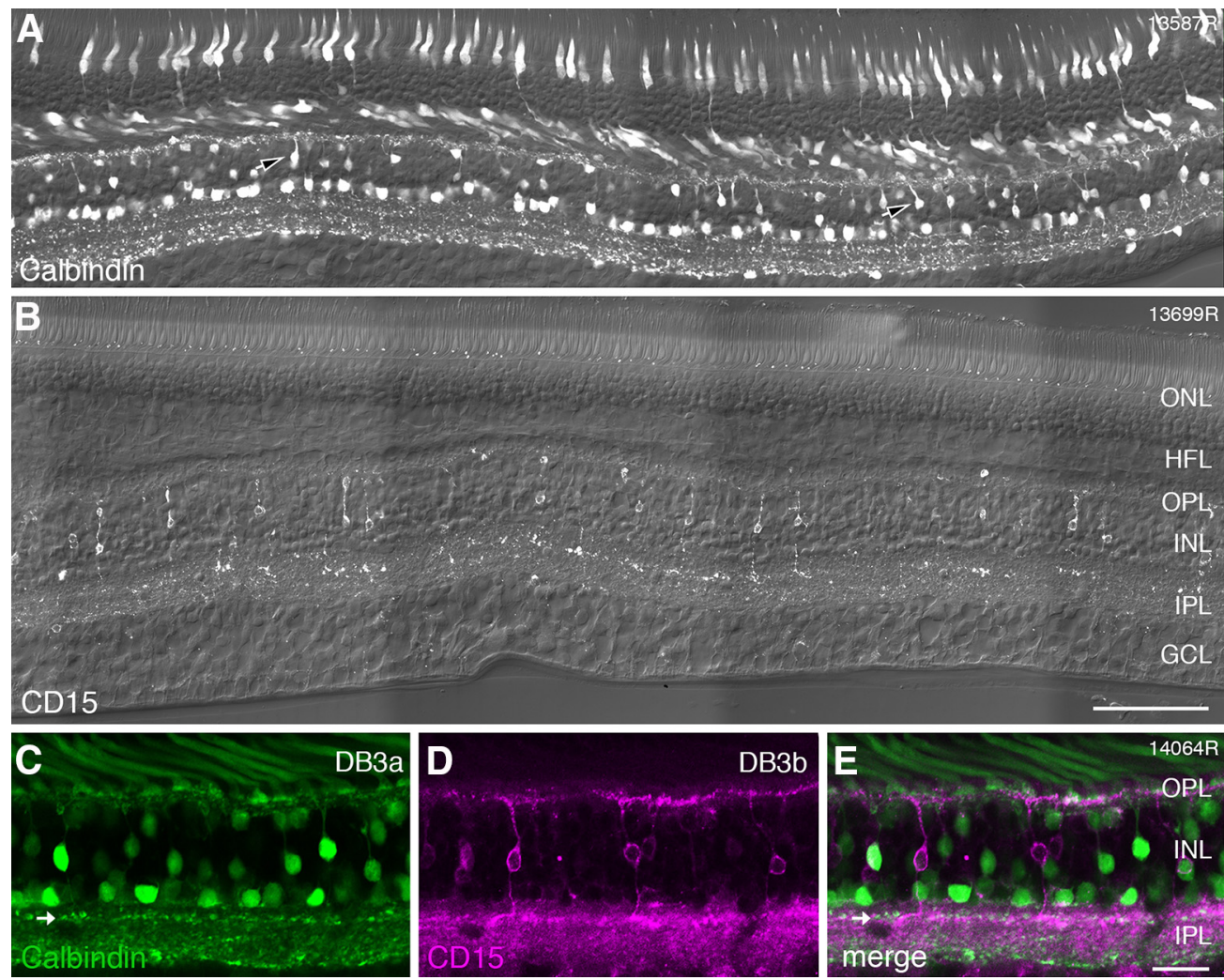

Figure 6. Immunohistochemical labeling of DB3a and DB3b cells. A, Confocal image of a vibratome section from preparation \#13587 (central retina) stained with antibodies against calbindin, imaged with Nomarski optics to reveal retinal layers. Calbindin expression can be observed in cone photoreceptors, horizontal cells, amacrine cells, and in DB3a bipolar cells (arrowheads). B. Confocal image of a vibratome section from preparation \#13699 (central retina) labeled with antibodies against CD15 and imaged with Nomarski optics. Expression of CD15 is restricted to DB3b bipolar cells. C-E, Region of interest from a section double labeled with antibodies against calbindin (green, DB3a cells) and antibodies against CD15 (magenta, DB3b cells). DB3a and DB3b cells form separate populations. The axon terminals of DB3a cells are indicated by arrows and are located slightly more sclerad than the axon terminals of DB3b cells. ONL: outer nuclear layer, HFL: Henle fiber layer, OPL: outer plexiform layer, INL: inner nuclear layer, IPL: inner plexiform layer, GCL: ganglion cell layer. Scale bars: $100 \mu \mathrm{m}(\boldsymbol{B}$, applies to $\boldsymbol{A}, \boldsymbol{B})$ and $25 \mu \mathrm{m}(\boldsymbol{E}$, applies to $(-\boldsymbol{E})$.

We measured the diameter of the axonal terminals for reconstructed midget bipolar cells at 1-, 4-, and 10-mm eccentricity (Fig. $5 A-C$ ). The average axon terminal diameter was $10 \mu \mathrm{m}$ $( \pm 1.8 \mu \mathrm{m}, n=10)$ at 1 - $\mathrm{mm}$ eccentricity, $16.7 \mu \mathrm{m}( \pm 2.2 \mu \mathrm{m}$, $n=10)$ at $4-\mathrm{mm}$ eccentricity, and $20.1 \mu \mathrm{m}( \pm 3.1 \mu \mathrm{m}, n=10)$ at $10-\mathrm{mm}$ eccentricity. We used measurements of dendritic field diameters of midget ganglion cells from published data (Dacey and Petersen, 1992) and divided the average dendritic field area by the axon terminal area of midget bipolar cells. This result indicates that each midget bipolar cell provides input to one midget ganglion cell at $1 \mathrm{~mm}$, increasing to over 10 midget bipolar cells converging onto each midget ganglion cell at 10 $\mathrm{mm}$. Kolb and Marshak (2003) reported compatible values for central and mid-peripheral retina but lower convergence $(\sim 4: 1)$ from midget bipolar to midget ganglion cells in peripheral retina.

\section{DB3a and DB3b cells}

DB cell types involved with OFF-parasol cells were identified with antibodies against calbindin (DB3a) and antibodies against CD15 (DB3b). Figure 6A shows a vertical section labeled with antibodies against calbindin. Immunoreactivity is present in cone photoreceptors, and in the inner nuclear layer, it is localized 



Figure 7. Spatial density of DB3a and DB3b bipolar cells. $\boldsymbol{A}$, Density of DB3a cells quantified using antibodies against calbindin in six preparations. $\boldsymbol{B}$, Data from $\boldsymbol{A}$ fit to a sum of exponents curve to illustrate the spatial density of DB3a cells across temporal retina. C, The density of DB3b cells plotted against eccentricity for five preparations. DB3b cells were identified with antibodies against CD15. D, Pooled data across these five preparations fit to a sum of exponents curve to show the population density of DB3a cells up to $15 \mathrm{~mm}$ temporal to the fovea. DB3a and DB3b cells have comparable densities across the retina. Error bars in $\boldsymbol{B}, \boldsymbol{D}$ (in many cases smaller than the marker symbols) show SDs.

to horizontal, bipolar, and amacrine cells. The axon terminals of calbindinlabeled DB3a cells form a distinct band in the OFF sublamina close to the middle of the inner plexiform layer. Two other bands can be distinguished in the inner plexiform layer: one is located in the ON sublamina close to its center and the other is located at the border with the ganglion cell layer. These bands are respectively formed by the processes of ON starburst amacrine, and the dendrites of inner stratifying melanopsinexpressing ganglion cells (Chandra et al., 2019).

Antibodies against CD15 (Fig. 6B) revealed a single bipolar cell type, the DB3b cell, which stratifies at nearly the same level as the DB3a cell in stratum 2 of the inner plexiform layer (Haverkamp et al., 2003; Puthussery et al., 2013). Antibodies against CD15 in human also revealed weak expression in the ganglion cell layer and diffuse expression across the inner plexiform layer (Fig. 6B). In doublelabeled sections, it becomes obvious that DB3a and DB3b cells form distinct nonoverlapping populations (Fig. $6 C-E$ ). This finding is consistent with recent RNA sequencing of the macaque retina which showed that $\mathrm{DB} 3 \mathrm{a}$ and $\mathrm{DB} 3 \mathrm{~b}$ cells have distinct molecular signatures (Peng et al., 2019).

We quantified the spatial density of DB3a and DB3b cells from 19 sections in six preparations. As shown in Figure 7, the two bipolar types follow a very similar distribution. The first DB3a cells appear $100 \mu \mathrm{m}$ from the foveal center and the first DB3b cells are present at $180 \mu \mathrm{m}$ temporal to the fovea. Both cell types have similar peak density at around 1-mm eccentricity. The average peak density of DB3a cells is 3900 cells $/ \mathrm{mm}^{2}$ (range
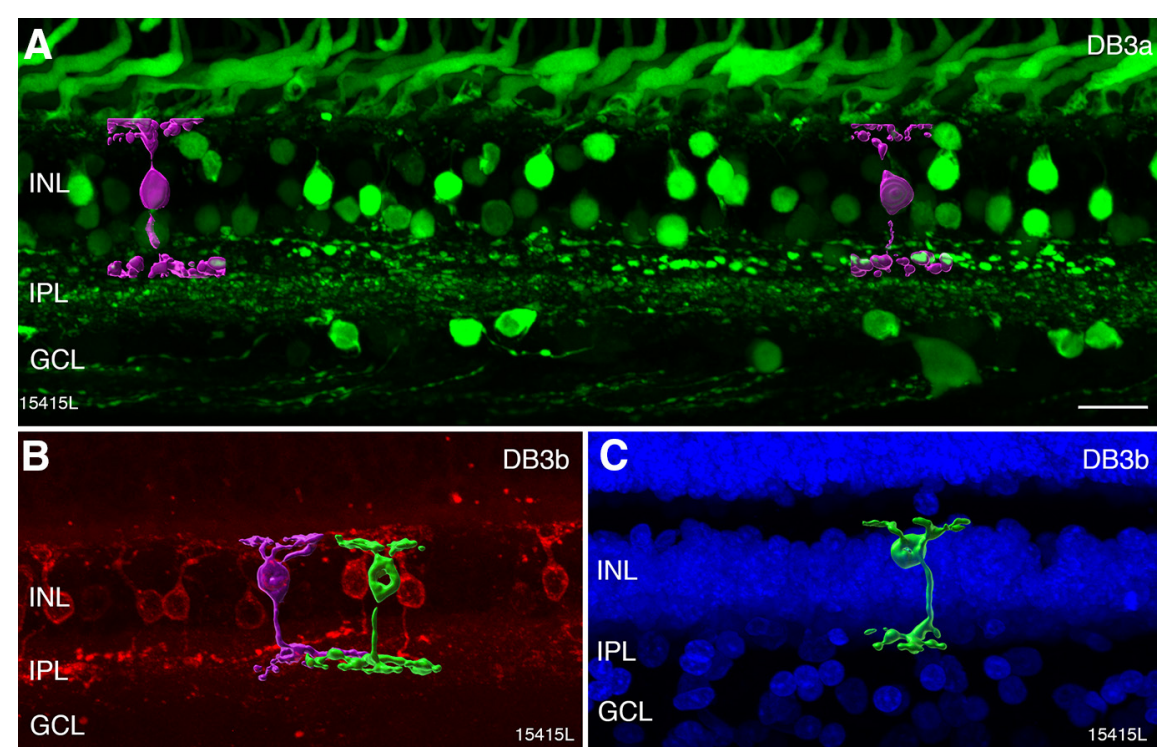

Figure 8. Reconstructions of DB3a and DB3b bipolar cells. Confocal images and three-dimensional reconstructions of DB cells from immunolabeled vertical sections. $A$, DB3a bipolar cells (magenta) reconstructed from a section labeled with antibodies against calbindin (green) in mid-peripheral $(5 \mathrm{~mm}$ ) retina. $\boldsymbol{B}, \boldsymbol{C}, \mathrm{DB} 3 \mathrm{~b}$ cells (green and magenta) reconstructed from a section labeled with antibodies against CD15 (red) in far peripheral $(8-10 \mathrm{~mm})$ retina. DAPI nuclear stain is shown in blue. INL: inner nuclear layer, IPL: inner plexiform layer, GCL: ganglion cell layer. Scale bar: $20 \mu \mathrm{m}(\boldsymbol{A}$, applies to $\boldsymbol{A}-\boldsymbol{C})$.

$4000-7000$ cells $/ \mathrm{mm}^{2}$ ). The average peak density of DB3b cells is close to 3500 cells $/ \mathrm{mm}^{2}$ (range $3000-7000$ cells $/ \mathrm{mm}^{2}$ ). The density for both DB3a and DB3b cells decreases in peripheral retina to fall below 1500 cells $/ \mathrm{mm}^{2}$ by $10-\mathrm{mm}$ eccentricity. Taken together, our results suggest that the density of DB3a and DB3b cells is well-matched across the retina.

Figure 8 shows reconstructions of calbindin-labeled DB3a cells (Fig. 8A) and CD15-labeled DB3b cells (Fig. 8B,C). The axon terminal diameter of DB3a and DB3b cells was measured from reconstructed cells in two preparations (\#14064 and $\# 15415)$. For DB3a cells, the average axon terminal diameter was 
$25 \mu \mathrm{m}( \pm 0.7 \mu \mathrm{m}, n=2), 26.2 \mu \mathrm{m}( \pm 2.4 \mu \mathrm{m}, n=5)$, and $26 \mu \mathrm{m}$ $( \pm 4.0 \mu \mathrm{m}, n=5)$ at 1,4 , and $9 \mathrm{~mm}$, respectively. For DB3b cells, the axon terminal diameter was $20.7 \mu \mathrm{m}( \pm 0.6 \mu \mathrm{m}, n=2)$, $29.2 \mu \mathrm{m}( \pm 2.8 \mu \mathrm{m}, n=5)$, and $35 \mu \mathrm{m}( \pm 4.0 \mu \mathrm{m}, n=5)$ at 1,4 , and $9 \mathrm{~mm}$, respectively. The DB3a terminals were difficult to isolate, and the expression of CD15 was poor in some sections, hence our measurements of DB3a and DB3b axon terminal diameter should be regarded as approximations.

In comparison to OFF-midget bipolar cells (Figs. 3, 5), DB3a and DB3b cells have a larger axon terminal diameter and a lower density across the retina. The OFF midget bipolar cells outnumber DB3a and DB3b cells (combined) by a ratio of 3:1 across the retina. In central retina the axon terminal diameter of OFFmidget bipolar cells is less than half that of DB cells. Our results imply high convergence between cones and DB cells and reflect the lower density of parasol ganglion cells compared with midget ganglion cells across the retina (Rodieck et al., 1985; Dacey and Petersen, 1992).

\section{Ganglion cells}

We identified ganglion cells by their immunoreactivity to antibodies against RBPMS (Kwong et al., 2010; Rodriguez et al., 2014). As shown in Figure 9A-F, RBPMS was localized to most somas in the ganglion cell layer, whereas presumed displaced amacrine cells were not labeled (Fig. 9B-F, arrows). Consistent with previous reports (Polyak, 1941; Curcio and Allen, 1990; Grünert et al., 1993), some ganglion cells as well as other cell types were observed within the foveal pit (Fig. 9A).

In two preparations (\#13699 and \#14064), antibodies against the calcium binding protein parvalbumin, which label a large proportion of cells in the ganglion cell layer in human retina (de Souza et al., 2016; Kántor et al., 2016) were applied. In order to determine whether ganglion cells are parvalbumin positive, two vertical sections from two preparations (\#15415 and \#15649) were double labeled with antibodies against parvalbumin and antibodies against RBPMS (Fig. 9G-J). Double-labeled cells were counted between 0 - and 6-mm eccentricity. On average, $92 \%$ of RBPMS-labeled ganglion cells were also labeled for parvalbumin. This proportion varied between $80 \%$ and $100 \%$ for individual regions and was not dependent on eccentricity, indicating that a small population of ganglion cells is parvalbumin negative.

Ganglion cell density was determined from five preparations in central retina and two preparations in mid-peripheral and far peripheral retina, using 10 vibratome sections labeled for RBPMS (\#13587, \#15415, \#15649) and three sections labeled for parvalbumin (\#13699, \#14064). The results are comparable in all preparations, but the peak ganglion cell density varies between individuals (range $28,000-50,000$ cells $/ \mathrm{mm}^{2}$; Fig. $9 \mathrm{~K}$ ). The average peak density of 34,000 cells $/ \mathrm{mm}^{2}$ at $1-\mathrm{mm}$ eccentricity falls at a steep rate within the central $3 \mathrm{~mm}$ temporal to the fovea, and then more gradually to 300 cells $/ \mathrm{mm}^{2}$ at $12-\mathrm{mm}$ eccentricity (Fig. 9L). Similar results were obtained by Curcio and Allen (1990), who reported a 2-fold variation in ganglion cell density between individuals and added that such individual differences imply a large variation in the total number of ganglion cells serving central vision.

As noted above, we did not observe any clear age-related changes in cell density. For example, preparations from older donors (\#15415 and \#13699) showed comparable ganglion cell densities to retinas from younger donors (\#15469; Fig. 9K). Recent data are inconclusive regarding age-related changes in ganglion cell density, with some reports indicating changes are most pronounced past 60 years of age (Yoshioka et al., 2017), and others suggesting decrease in ganglion cell density occurs gradually from late $30 \mathrm{~s}$ onwards (Tong et al., 2019). Our sample size is too small to contribute to this debate. In summary, the ganglion cell density across the human retina determined here from vertical sections is in good agreement with previous studies using whole mount preparations (Curcio and Allen, 1990) and indicates that our bipolar cell measurements fit into a picture which is congruent with estimates of other cell types in human retina.

As outlined above, cone photoreceptors and OFF-midget bipolar cells exist in equal proportions up to $10-\mathrm{mm}$ eccentricity (Fig. 4), indicating that convergence in the midget pathway occurs in the inner retina where multiple midget bipolar cells contact a single midget ganglion cell. Here, we compared the density of cones, OFF-midget bipolar cells and ganglion cells for two individual preparations (Fig. 10A,B) as well as the pooled densities across all preparations (Fig. 10C) from 1- to 10 -mm eccentricity. Decline in ganglion cell density from central to peripheral retina is much steeper than that of cones or midget bipolar cells. Across all preparations, ganglion cell density exceeds that of cones between 1 - and 2-mm eccentricity. The density of ganglion cells falls below that of cone photoreceptors at $2.3 \mathrm{~mm}\left(7.9^{\circ}\right)$ in preparation $\# 13587,3.3 \mathrm{~mm}\left(11.4^{\circ}\right)$ in preparation \#14064, and at $2.6 \mathrm{~mm}$ $\left(8.9^{\circ}\right)$ when data are pooled from all preparations. These data are consistent with findings in macaque retina which show that the sampling density of ganglion cells decreases beyond $15^{\circ}$ (3-4 mm; Wässle et al., 1990). Convergence in foveal retina needs to take the receptoral displacement into account and is discussed separately below.

In addition to parvalbumin positive/RBPMS positive ganglion cells, we found cells in the ganglion cell layer which were parvalbumin positive but RBPMS negative (data not shown). These cells were usually located close to the border with the inner nuclear layer and had relatively small somas. Thus, these cells are presumed to be displaced amacrine cells. The density of parvalbumin positive displaced amacrine cells was quantified for one preparation (\#15415) between 0.3 - and 6-mm eccentricity. The peak density was 1400 cells $/ \mathrm{mm}^{2}$ between 1 - and $2-\mathrm{mm}$ eccentricity and fell to 300 cells $/ \mathrm{mm}^{2}$ by $6-\mathrm{mm}$ eccentricity.

\section{Receptoral and postreceptoral displacement}

As outlined above (Fig. 2), in the center of the fovea, cone photoreceptors are densely packed, and the remaining layers of the retina are displaced away from the center. We determined this lateral displacement (see Materials and Methods) in the same preparations as used to determine bipolar and ganglion cell densities described above. We first measured the receptoral displacement (Henle fiber length), then we measured the postreceptoral displacement between the dendritic contacts of bipolar cells with cones and their axonal terminals (contacts with retinal ganglion cells). We ignored the additional displacement due to the offset of the ganglion cell dendritic tree from the soma (Perry and Cowey, 1988) since this accounts for $<1 \%$ of total lateral displacement (Sjöstrand et al., 1999).

Figure $11 A-C$ shows that the longest Henle fibers (300$400 \mu \mathrm{m}$ ) are found at cone soma eccentricities between 0.5 and 1 $\mathrm{mm}$ temporal. Outside the fovea, Henle fiber length decreased to $<100 \mu \mathrm{m}$ by $2.5 \mathrm{~mm}$ with some variation between preparations (Fig. 11C). By $\sim 6-\mathrm{mm}$ eccentricity, cone photoreceptor somas are vertically aligned with their pedicles (Fig. $2 E$ ), and thus there is no receptoral displacement. These results are consistent with previous reports in human (Polyak, 1941; Sjöstrand et al., 1999) 

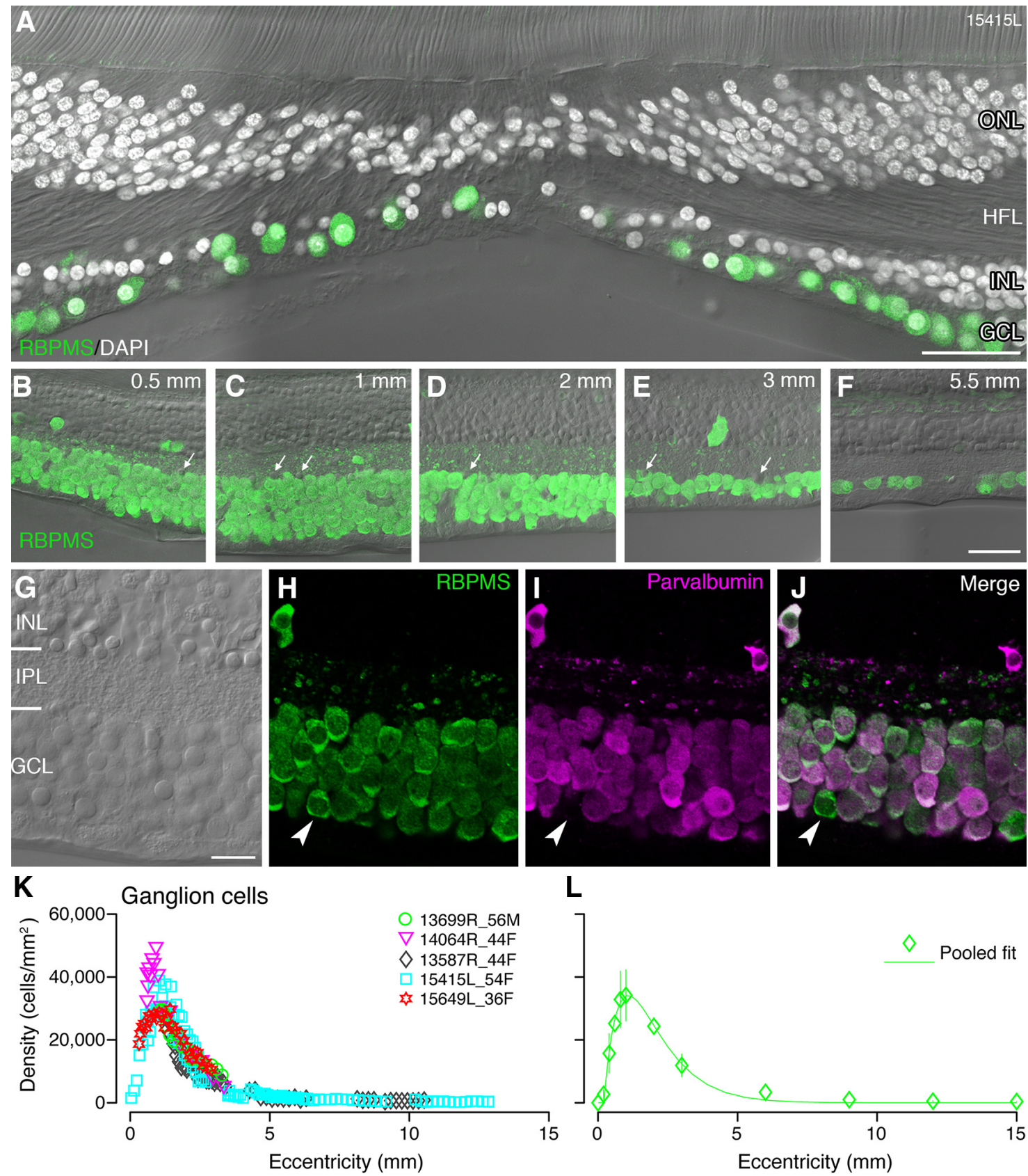

Figure 9. Retinal ganglion cells: immunolabeling and spatial density. $\boldsymbol{A}$, Confocal micrograph of a vertical section through the fovea of preparation \#15415 showing DAPI-labeled cell nuclei (white) and RBPMS-labeled ganglion cell somas (green) within 250- $\mu \mathrm{m}$ radius of the foveal center. In addition to RBPMS-labeled ganglion cell somas, other cell nuclei can be observed on the foveal floor. $\boldsymbol{B}-\boldsymbol{F}$, Regions of interest from vertical sections of the same preparation shown in A showing RBPMS-positive ganglion cells together with Nomarski optics. Occasional displaced ganglion cells can be observed in the inner nuclear layer. Arrows point to cells in the ganglion cell layer which do not express RBPMS. G-J, Confocal images of a region of interest from a vertical section at 1.2-mm eccentricity labeled with antibodies against parvalbumin (magenta) and antibodies against RBPMS (green). $\boldsymbol{G}$, Nomarski optics reveals the layers of the retina. $\boldsymbol{H}$, RBPMS-labeled ganglion cell somas. I, Parvalbumin-labeled cells in the ganglion cell layer: $J$, The merged image shows that most ganglion cells are double labeled for RBPMS and parvalbumin but there is a small population of ganglion cells (arrowheads) that do not express parvalbumin. $\boldsymbol{K}, \boldsymbol{L}$, Ganglion cell density is shown relative to eccentricity. Data from five preparations is shown in $\boldsymbol{K}$ and average density across all preparations, fit to a sum of exponents, is shown in $L$. Error bars (in many cases smaller than the marker symbols) show SDs. ONL: outer nuclear layer, HFL: Henle fiber layer, INL: inner nuclear layer, IPL: inner plexiform layer, GCL: ganglion cell layer. Scale bars: $50 \mu \mathrm{m}(\boldsymbol{A}), 50 \mu \mathrm{m}(\boldsymbol{B}$, applies to $\boldsymbol{B}-\boldsymbol{F})$, and $20 \mu \mathrm{m}(\boldsymbol{G}$, applies to $\mathbf{G}-\boldsymbol{J})$.

and macaque retinas (Perry and Cowey, 1988; Schein, 1988; Bringmann et al., 2018).

Postreceptoral (bipolar cell) displacement was measured at eccentricities ranging from 0.24 to $8.6 \mathrm{~mm}$ along the temporal axis from recoverin labeled OFF-midget bipolar (Fig. $3 A-D)$, calbindin-labeled DB3a (Fig. 6A,C) or CD15-labeled DB3b (Fig. 6B, $D)$ cells; all these measurements yielded comparable results. Individual variability is less evident in postreceptoral displacement compared with receptoral displacement (Fig. 11D). The largest displacement occurs between 0.3 - and 0.8 - mm eccentricity with average magnitude $55 \mu \mathrm{m}$ and maximum $70 \mu \mathrm{m}$ (Fig. $11 D$ ). From $\sim 2.5$-mm eccentricity, there is no appreciable displacement. Similar values were reported by Sjöstrand et al. (1999) in human retina and by Perry and Cowey (1988) in macaque retina.

The peak total displacement was $389 \mu \mathrm{m}$ (range $\sim 300$ $400 \mu \mathrm{m})$ at $0.5 \mathrm{~mm}$ from the foveal center. Previous studies of human retina report a total displacement in the range of $370 \mu \mathrm{m}$ 

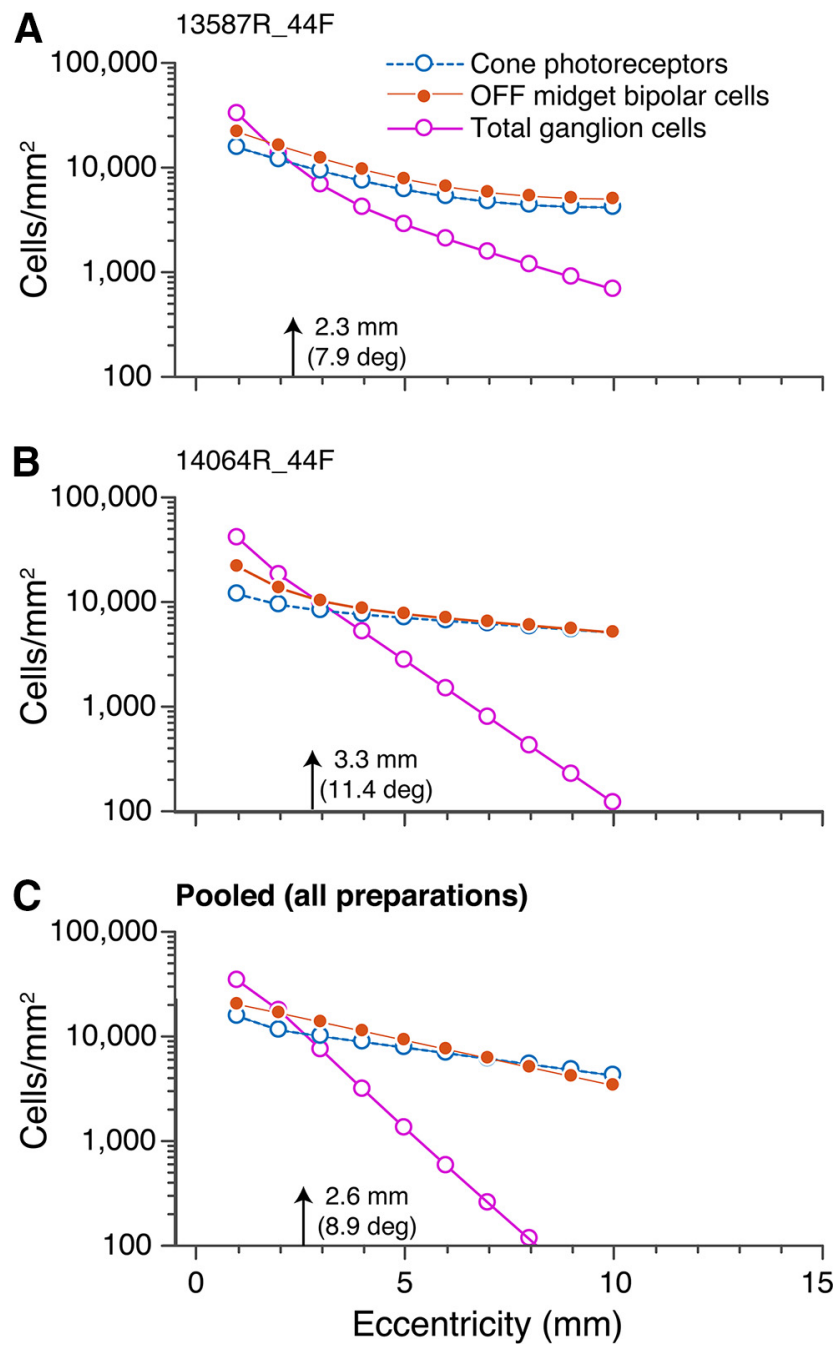

Figure 10. Density of cone photoreceptors, OFF-midget bipolar cells, and ganglion cells. The average densities of cone photoreceptors (blue), OFF-midget bipolar cells (orange), and ganglion cells (pink) are shown on a logarithmic scale from 1- to 10-mm eccentricity for preparations \#13587 (A) and \#14064 $(\boldsymbol{B})$, as well as the average across all preparations $(n=6 ; C)$.

(Sjöstrand et al., 1999) to $526 \mu \mathrm{m}$ (Drasdo et al., 2007). Drasdo et al. (2007) attribute this interstudy variability to meridional differences, but no such differences were reported in macaque retinas (Perry and Cowey, 1988; Schein, 1988). Alternatively, Drasdo et al. (2007) may have overestimated displacement because of overcorrection for shrinkage and the exclusion of outliers. Overall, the peak total lateral displacement of $389 \mu \mathrm{m}$ obtained here is consistent with previous studies.

\section{Density variability}

It is clear from the foregoing results that there is variation in spatial density (both within and between individuals) for each measured population at any given eccentricity (Figs. $2 \mathrm{G}-\mathrm{J}, 3 E, 4 F, G, 7,9 K, L)$. It is therefore natural to question the extent to which conclusions based on six retinas can be applied to a larger population. Our study does not address this question directly, but our small sample can nevertheless provide rough upper and lower bounds to the densities and ratios calculated above. Table 4 compares mean density and $\mathrm{SD}$ of each cell population in central $(1 \mathrm{~mm})$, mid-peripheral
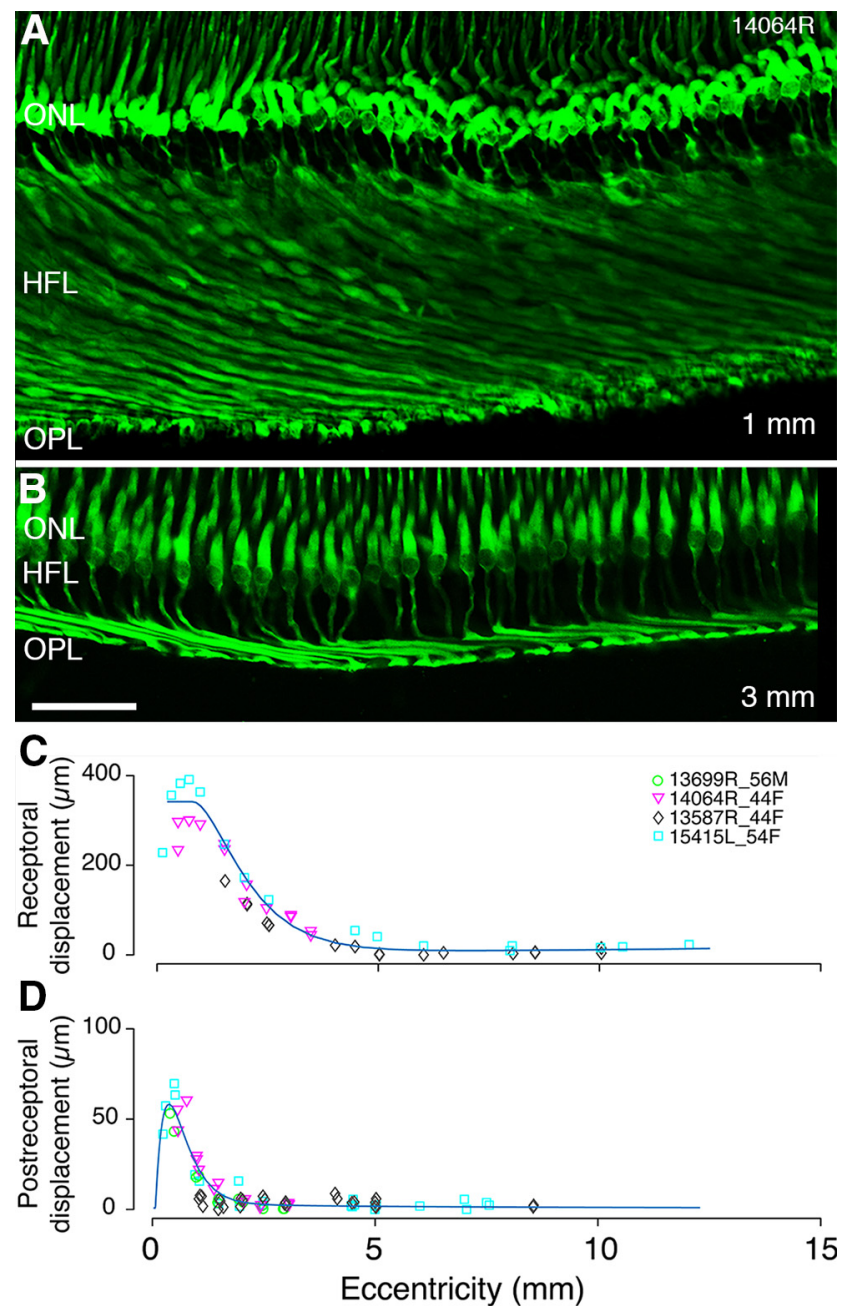

Figure 11. Lateral displacement. $\boldsymbol{A}, \boldsymbol{B}$, Confocal images of a vertical section through the fovea labeled with antibodies against cone arrestin. Eccentricities are indicated in the lower left corner. $\boldsymbol{C}$, The lateral distance of the cone pedicle from the soma is plotted as receptoral displacement on the $y$-axis. The eccentricity of the soma is plotted on the $x$-axis against the horizontal distance to the cone pedicle. $\boldsymbol{D}$, Postreceptoral displacement is plotted against eccentricity for three preparations. The displacement was measured from the center of the dendritic bouquet to the center of the axon terminal of calbindin, CD15, and recoverin labeled bipolar cells, respectively. On the $x$-axis, the distance of the center of the dendritic bouquet from the fovea is plotted as the assumed eccentricity of the cone pedicle. Curves show difference-of-exponentials functions. ONL: outer nuclear layer, HFL: Henle fiber layer, OPL: outer plexiform layer. Scale bar: $50 \mu \mathrm{m}(\boldsymbol{B}$, applies to $\boldsymbol{A}, \boldsymbol{B})$.

( $3 \mathrm{~mm})$, and far peripheral retina $(9 \mathrm{~mm})$. In most cases, the coefficient of variation (mean/SD) lies between $20 \%$ and $30 \%$, giving a rough estimate of variability expected at population level. For simplicity, we did not attempt a finergrained analysis of ratios between all measured cell populations.

\section{Parallel pathways in the fovea}

We used the density counts of cones, OFF-midget bipolar cells, DB3a, and ganglion cells (Fig. $12 A-D$, left panel) to determine the cumulative numbers of each cell type (Fig. $12 A-D$, right panel) within 2-mm eccentricity. We then accounted for receptoral displacement of bipolar cells and total displacement of ganglion cells to calculate cumulative cell numbers within the midget-parvocellular and parasol-magnocellular pathways (Fig. $12 A-D$, red dotted lines). 
Table 4. Spatial density in central and peripheral retina

\begin{tabular}{|c|c|c|c|c|c|c|}
\hline & Density (cells $/ \mathrm{mm}^{2}$ ) & CV (SD/mean) & Density (cells $/ \mathrm{mm}^{2}$ ) & CV (SD/mean) & Density (cells $/ \mathrm{mm}^{2}$ ) & $\overline{C V}$ (SD/mean) \\
\hline Eccentricity (mm) & 1 & 1 & 3 & 3 & 9 & 9 \\
\hline Cones (inner segment) & $14,841 \pm 2565(7)$ & $17.3 \%$ & $9257 \pm 1939(37)$ & $20.9 \%$ & $4541 \pm 635(54)$ & $14.0 \%$ \\
\hline S-cones (inner segment) & $1324 \pm 463(20)$ & $35.0 \%$ & $925 \pm 314(63)$ & $33.9 \%$ & $355 \pm 209(26)$ & $58.7 \%$ \\
\hline OFF midget bipolar cells & $21,424 \pm 3821(17)$ & $17.8 \%$ & $13,132 \pm 3359(62)$ & $25.6 \%$ & $6563 \pm 1152(15)$ & $17.5 \%$ \\
\hline DB3a cells & $3722 \pm 878(17)$ & $23.6 \%$ & $2513 \pm 820(47)$ & $32.6 \%$ & $1125 \pm 322(36)$ & $28.6 \%$ \\
\hline DB3b cells & $2949 \pm 0.781(10)$ & $26.5 \%$ & $3125 \pm 667(34)$ & $21.3 \%$ & $1282 \pm 219$ & $17.1 \%$ \\
\hline
\end{tabular}

Values show mean cell density (cells $\left./ \mathrm{mm}^{2}\right) \pm S D$. the number of observations is shown in parentheses. Abbreviation: $\mathrm{CV}$, coefficient of variation (SD/mean).
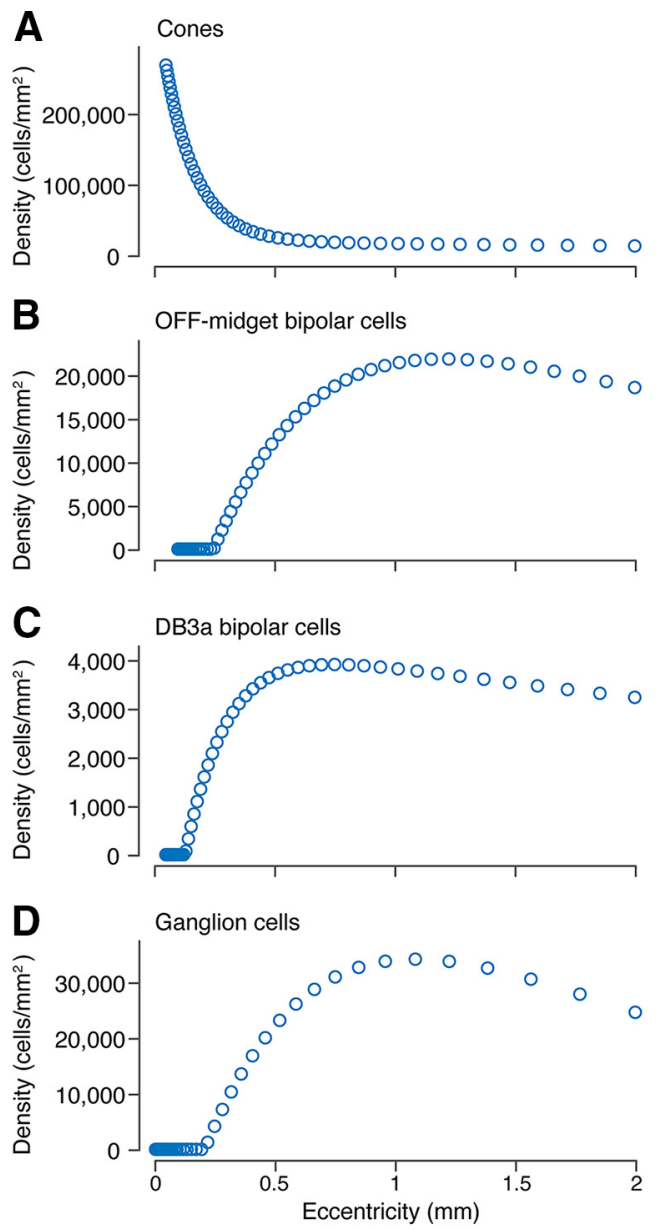

$\mathbf{E}$

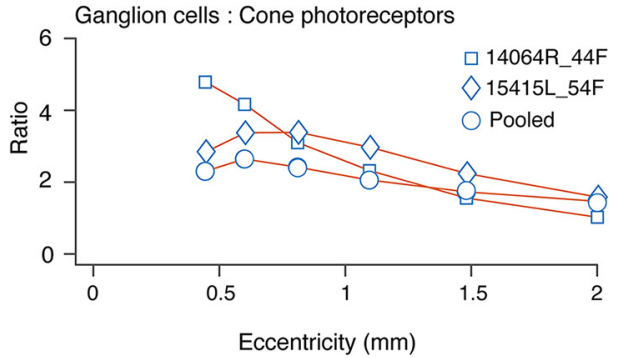

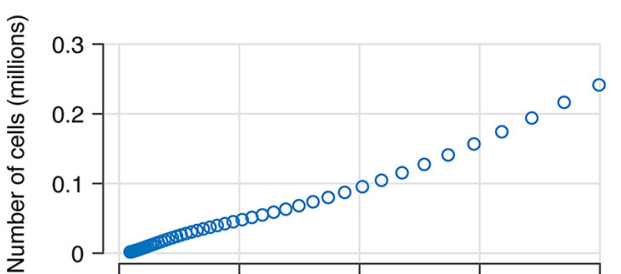
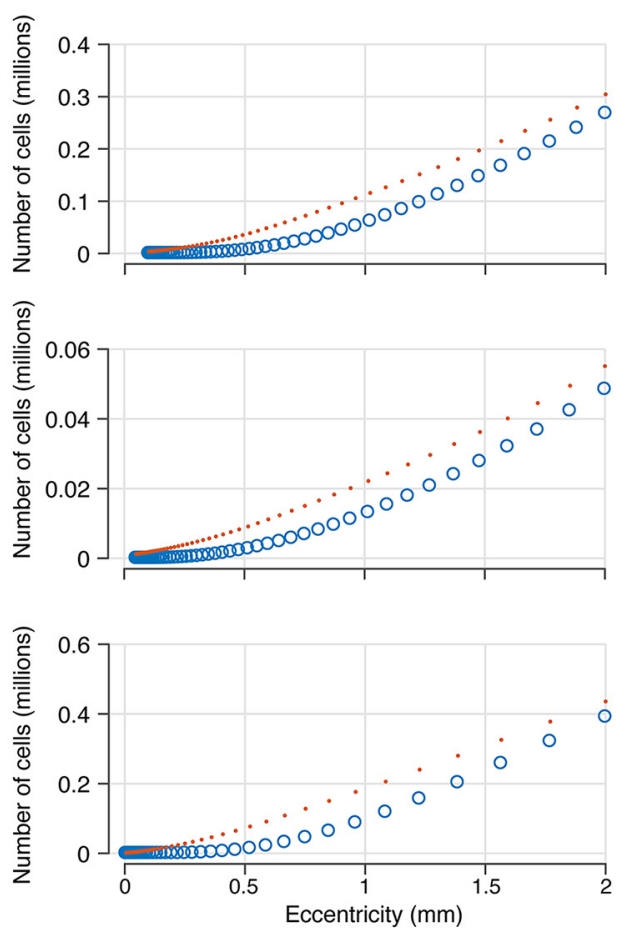

$\mathbf{F}$

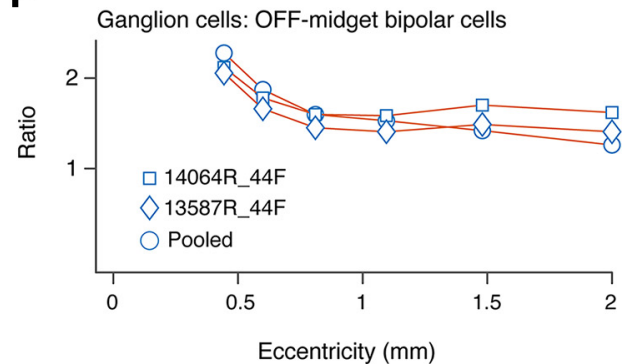

Figure 12. Cumulative density of cells in OFF-midget and OFF-parasol pathways of the retina. $\boldsymbol{A}-\boldsymbol{D}$, The panels on the left represent pooled average densities for cones, $0 \mathrm{FF}-$ midget bipolar cells, DB3a bipolar cells, and ganglion cells from 0- to 2-mm eccentricity. The panels on the right show the cumulative counts for each cell population across the same eccentricity range. The red dotted lines represent the cumulative numbers for each cell type adjusted for receptoral $(\boldsymbol{B}, \boldsymbol{C})$ and total lateral displacement $(\boldsymbol{D})$. $\boldsymbol{E}$, Ratio of ganglion cells to cones from 0.5 - to 2 -mm eccentricity interpolated from data in panels $\boldsymbol{A}, \boldsymbol{D}$. $\boldsymbol{F}$, Ratio of ganglion cells to OFF-midget bipolar cells interpolated from data in panels $\boldsymbol{B}, \boldsymbol{D}$. Circle symbols in $\boldsymbol{E}, \boldsymbol{F}$ show pooled data; diamond and square symbols show individual double-labeled cases. 


\section{Midget-parvocellular pathway}

The number of cones is 240,000 by $2-\mathrm{mm}$ eccentricity (Fig. $12 \mathrm{~A}$ ), and the number of OFF-midget bipolar cells is 300,000 by $2 \mathrm{~mm}$, taking Henle fiber displacement into account (Fig. 12B). The ratio of cones to OFF-midget bipolar cells is $1: 1$ at $0.4-\mathrm{mm}$ eccentricity, 1.2:1 at $0.5-\mathrm{mm}$ eccentricity, and $0.8: 1$ between $0.5-$ and 2 -mm eccentricity. Therefore, after accounting for receptoral displacement due to Henle fibers, the number of OFF-midget bipolar cells in central retina allows for a single OFF-midget bipolar cell for every cone.

\section{Parasol-magnocellular pathway}

At $1 \mathrm{~mm}$, the total number of DB3a cells is $\sim 22,200$ (Fig. 12C), and the total number of cones is $\sim 88,000$, which translates to four cones converging onto a single DB3a cell at the fovea. The ratio of cones to DB3a cells is fairly consistent across eccentricities. A similar pattern of convergence for DB3b cells is expected from the tightly matched densities of the two populations (Fig. $7 B, D)$. Previous estimates of convergence of cones to DB3a cells exist only at eccentricities beyond $3 \mathrm{~mm}$, and are in the range of 8-12 cones for each DB3a cell for macaque (Boycott and Wässle, 1991; Grünert et al., 1994; Tsukamoto and Omi, 2015) and marmoset (Luo et al., 1999) retinas. Our results thus show that multiple cone photoreceptors converge onto DB cells in foveal as well as peripheral primate retina.

\section{Ganglion cell sampling density}

At $1-\mathrm{mm}$ eccentricity, the total number of ganglion cells is close to 180,000 (Fig. 12D). Figure $12 E$ shows the ratio of ganglion cells to cones from 0.5 - to 2 -mm eccentricity after accounting for total lateral displacement. The ratio of ganglion cells to cones at $1 \mathrm{~mm}$ is $2.2: 1$. This ratio decreases from $1 \mathrm{~mm}$ onwards to a ratio of $1.5: 1$ by $2 \mathrm{~mm}$, as the sampling density of ganglion cells decreases. Over this eccentricity range the OFF-midget bipolar cells is over half the density of ganglion cells (mean 64.2\%; Fig. $12 F)$, consistent with dominance of the midget-parvocellular pathway at the fovea (Dacey, 1993; Liu et al., 2017). If OFFmidget ganglion cells likewise make up $64 \%$ of all ganglion cells at the fovea, then the ratio of OFF-midget ganglion cells to OFFmidget bipolar cells would fall below unity (implying convergence of bipolar to ganglion cells) at eccentricities above 1.05 $\mathrm{mm}\left(3.6^{\circ}\right)$. These calculations based on the pooled data sample are supported by analysis of three retinas where the relevant populations were measured in the same sections, in double-labeled preparations (case \#14064, Fig. 12E,F; case \#15415, Fig. 12E; case $\# 13587$, Fig. $12 F$ ). In each case, the ratio of ganglion cells to cones exceeds 2.2:1 within the central-most $1.5 \mathrm{~mm}$, and midget bipolar cells are present at high density throughout foveal retina. In summary, at the fovea, a ratio of at least 2.2 ganglion cells for every cone allows for one-to-one connectivity of cones to midget ganglion cells, as well as the presence of parasol cells and other widefield cells at low densities.

\section{Comparison to human photopic acuity}

Finally, in Figure 13, we compare the resolving power of bipolar and ganglion cell arrays to achromatic grating resolution measured in photopic human vision (Anderson et al., 1991; Wilkinson et al., 2016). Such comparisons require assumptions and must be made with caution but can yield useful insights on the anatomic substrates of human visual performance. We calculated cell array acuity using the formulas described in Materials and Methods. Following Dacey (1993), we assumed that midget ganglion cells make up $95 \%$ of all ganglion cells in the
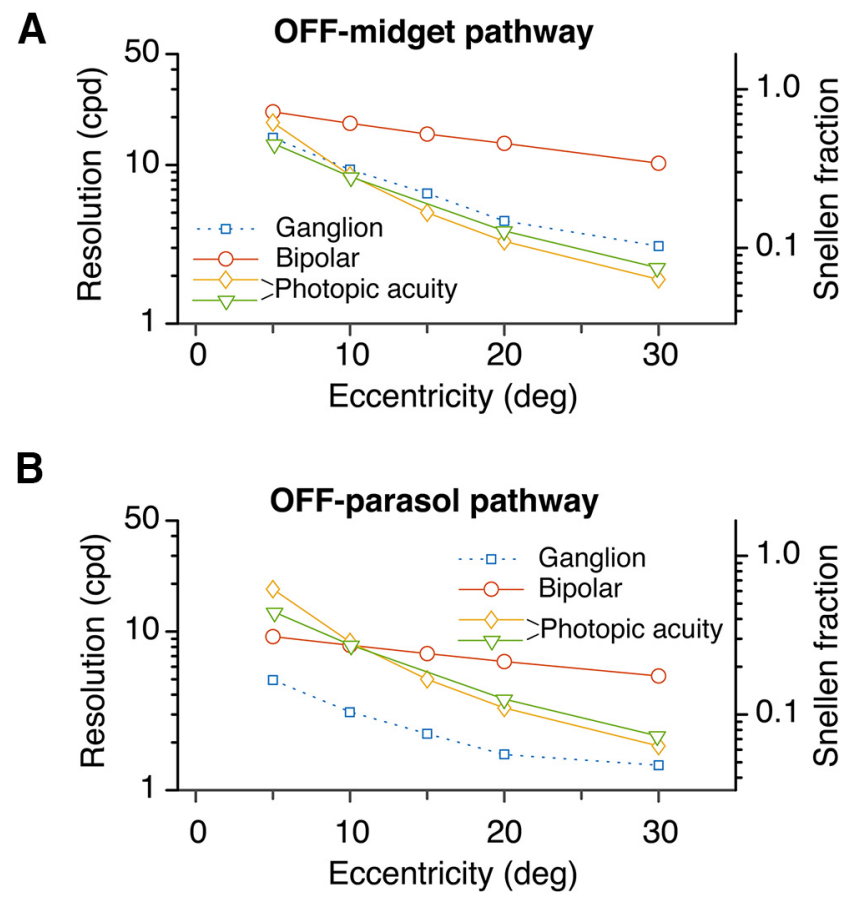

Figure 13. Comparison of cell array acuity to psychophysically measured photopic spatial acuity. A, Acuity of OFF-midget ganglion cell and OFF-midget bipolar cell arrays compared with two measures of human achromatic grating acuity [Anderson et al., 1991 (diamond symbols); Wilkinson et al., 2016 (triangle symbols)] across the eccentricity range $5-30^{\circ}$. Note the close correspondence of OFF-midget ganglion cell array acuity to the psychophysical measures. B, Comparison with OFF-DB cell (combined DB3a and DB3b) and parasol ganglion cell array acuity with the same psychophysical data. Note that parasol cell array acuity falls well below human acuity at all eccentricities.

central $10^{\circ}, 85 \%$ at $15^{\circ}, 70 \%$ at $20^{\circ}$, and $46 \%$ at $30^{\circ}$, and that parasol cells make up $10 \%$ of all ganglion cells throughout this eccentricity range. For simplicity, we did not take into account factors such as cell coupling (Vaney, 1994; Shlens et al., 2006) or the small proportion $(\sim 20 \%)$ of synaptic input from DB cells to midget ganglion cells (Tsukamoto and Omi, 2015).

Figure $13 \mathrm{~A}$ shows that acuity of the human OFF-midget ganglion cell array closely follows photopic grating acuity between $5^{\circ}$ and $30^{\circ}$. The OFF-midget bipolar array acuity is close to grating acuity at $5^{\circ}$, but is substantially higher at greater eccentricities, and falls less steeply than grating acuity to leave almost a log unit gap between the curves at $30^{\circ}$. In other words, although human grating acuity falls to only $6 \%$ of foveal acuity (Snellen fraction) by $30^{\circ}$ eccentricity, the midget bipolar array acuity is much higher (close to $30 \%$ Snellen fraction). A similar pattern of results is evident for the OFF-parasol pathway (Fig. 13B), with the clear exception that OFF-parasol ganglion cell acuity is well below human grating acuity at all eccentricities. Overall, this result agrees with the studies cited above (Wilkinson et al., 2016; Anderson et al., 1991; see also Merigan and Katz, 1990), indicating that the midget-parvocellular pathway is a more compelling anatomic basis of human photopic acuity than is the parasol-magnocellular pathway. We return to this question in Discussion.

\section{Discussion}

Previous studies of human retina have quantified photoreceptors (Curcio et al., 1990) and ganglion cells (Curcio and Allen, 1990), but cone bipolar pathways have remained undescribed. Here, we have four main findings. First, the OFF-midget-bipolar cells in 
human retina preserve the spatial and chromatic signals from the cone array, transmitting them to the inner plexiform layer from the fovea to at least $30^{\circ}$ eccentricity (Figs. 4, 5, 10, 12). Second, OFF-parasol contacting bipolar cells (DB3a, DB3b) are also present throughout the central $30^{\circ}$, at combined density close to one-third that of the midget bipolar array (Figs. 6, 7, 12). Third, ganglion cell and bipolar cell density in the human fovea is consistent with divergence of foveal cone signals to parallel midget and parasol pathways (Fig. 12). Finally, midget bipolar and ganglion cell density in peripheral retina can support the spatial resolution of human photopic vision (Fig. 13). In the following, we discuss these findings in context of other studies of human and non-human primate retina.

\section{The off-midget-parvocellular pathway}

The peak density of OFF-midget bipolar cells is 22,000 cells/ $\mathrm{mm}^{2}$, which is very close to peak density estimated at 22,300 cells $/ \mathrm{mm}^{2}$ in macaque retina (Wässle et al., 1994). We found that cone photoreceptors and OFF-midget bipolar cells are present in a one-to-one ratio to at least $10-\mathrm{mm}$ eccentricity, also as previously shown for macaque retina (Wässle et al., 1994). By contrast, in marmoset monkeys, one-to-one connectivity of cones to midget bipolar cells is restricted to the fovea (Chan et al., 2001; Telkes et al., 2008; Weltzien et al., 2015).

One-to-one connections of cones to bipolar cells implies preservation of the chromatic specificity of the long/medium (L/M) wavelength cone arrays in inner peripheral retina. Some (but not all) electrophysiological studies in macaque retina (Martin et al., 2001; Solomon et al., 2005; Field et al., 2010; Wool et al., 2018) and psychophysical studies in human (Abramov et al., 1991; Mullen and Beaudot, 2002; Mullen et al., 2005) show that chromatic sensitivity is slightly above that predicted by random "hit or miss" connections with $\mathrm{L} / \mathrm{M}$ cones.

An obvious question arising is whether the same patterns of distribution and connectivity that we see in the OFF-midget pathway are present in the ON-midget pathway. Ahmad and colleagues (2003) report twice as many OFF-DB cells than ON-DB cells in the fovea, but comparable numbers of OFF-midget and $\mathrm{ON}$-midget bipolar cells. In macaque and human, receptive and dendritic fields of ON-parasol cells are larger than that of OFFparasol cells (Dacey and Petersen, 1992; Chichilnisky and Kalmar, 2002), implying lower densities of ON-parasol than OFF-parasol cells, but whether this difference is reflected in bipolar cell densities needs to be determined.

\section{Off-parasol-magnocellular pathway}

The peak density of DB3a cells in human retina ranges between 4000 and 7000 cells $/ \mathrm{mm}^{2}$. Similar values were obtained in macaque (Martin and Grünert, 1992) and marmoset retinas (Weltzien et al., 2015). The peak density of DB3b cells ranged from 3000 to 7000 cells $/ \mathrm{mm}^{2}$ and thus DB3b cells exist in equal proportions to DB3a cells across human retina (Fig. 7). Comparable densities across species likely reflect consistencies in organization of the parasol-magnocellular pathway across primates (Ghosh et al., 1996; Jacoby et al., 2000; Masri et al., 2016).

We found the numerical convergence of cones to DB cells was close to $4: 1$, and that the combined density of DB3a and DB3b cells was close to one third that of midget bipolar cells across the retina. These observations are consistent with the functional properties of high sensitivity to contrast and weak chromatic selectivity which characterizes the parasol-magnocellular pathway. The OFF parasol pathway relies in part on a large receptive field (Schiller et al., 1990; Petrusca et al., 2007; Crook et al., 2008) and specializations of DB cell ion channels (Puthussery et al., 2013) to respond to high temporal frequency stimuli, and to detect motion and flicker in visual space.

\section{Foveal sampling density}

We measured receptoral displacement at the fovea by directly tracing the Henle fibers in sections through the center of the fovea. A degree of error in this method can arise from tissue distortions and the potential for misidentifying the foveal center (Packer et al., 1989; Curcio et al., 1990). Nonetheless, our results are consistent with previous estimates from Sjöstrand et al. (1999) and recent work by Bringmann et al. (2018) in human retina.

We estimate a ratio of 2.2 ganglion cells per cone in the fovea after accounting for total lateral displacement. Previous estimates in human fovea exist in the range of 1:1 (Missotten, 1974), 2:1 (Curcio and Allen, 1990; Drasdo et al., 2007), and 3-4:1 (Sjöstrand et al., 1999). Midget ganglion cells make up at least $80 \%$ of the ganglion cells in human fovea (Rodieck et al., 1985; Dacey, 1993; Yan et al., 2020), and existing evidence supports the presence of one ON-midget and one OFF-midget ganglion cell for every foveal cone (Kolb and DeKorver, 1991). It is assumed that the remaining $10-20 \%$ of ganglion cells in the human fovea consists of parasol cells, small bistratified and widefield ganglion cells, as shown for non-human primates (Dacey, 1993; Grünert et al., 1994; Percival et al., 2013; Sinha et al., 2017; Peng et al., 2019). It follows that estimates lower than 2:1 ganglion cells per cone do not allow for the presence of foveal non-midget ganglion cells.

Finally, we note that our estimates of peak cone density at the fovea for two retinas (respectively, 150,667 and 141,935 cells $/ \mathrm{mm}^{2}$ ) correspond to Nyquist frequencies 60.5 and 58.7 cycles $/{ }^{\circ}$ (cpd), which is close to foveal achromatic acuity values $(\sim 45 \mathrm{cpd})$ reported by Anderson et al. (1991) and Wilkinson et al. (2016).

\section{Functional roles of $P$ and $M$ pathways}

Our anatomic results have some relevance to a debate over the role of midget-parvocellular (P) and parasol-magnocellular (M) pathways in spatial vision, which was ignited over 30 years ago (Shapley and Perry, 1986). The literature on this topic is extensive, and the details have been reviewed elsewhere (Lee et al., 2010). The nub of it lies in discrepancies between anatomy and function of midget ganglion (P) cells. As shown here and elsewhere, the midget-parvocellular pathway in the retina clearly has a much finer spatial grain than does the parasol-magnocellular (M) pathway (Kolb and DeKorver, 1991; Calkins et al., 1994; Boycott and Wässle, 1999). But (1) achromatic contrast sensitivity of individual $\mathrm{P}$ cells is much lower than human achromatic contrast sensitivity (for review, see Shapley and Perry, 1986), (2) $\mathrm{P}$ and $\mathrm{M}$ cells have comparable spatial acuity at low contrast (Hicks et al., 1983; Blakemore and Vital-Durand, 1986), and (3) $\mathrm{M}$ cells are a more viable substrate for the (high spatial resolution) luminance channel than are P cells (for review, see Lennie et al., 1993; Lee et al., 2010). Our anatomic results cannot resolve these specific functional questions (or, indeed, the broader question whether the brain uses only one ganglion cell type to achieve high-acuity vision: Schiller et al., 1990; Merigan and Maunsell, 1993), but they bring two new points to bear on the debate. First, our data (Fig. 13) have confirmed psychophysical predictions that parasol cell array acuity is too low to support photopic acuity at any retinal eccentricity (Anderson et al., 1991; Wilkinson et al., 2016). Second, high density of midget bipolar cells in peripheral retina has been suggested as a sign of specialization of the midget pathway for peripheral red/green color vision (Martin and Grünert, 1992; Wässle et al., 1994; Lee et al., 2010). But here 
we find that the DB3a and DB3b cells which feed parasol cells are present at high density in peripheral retina. This result implies that high density of bipolar cells in peripheral retina is a general feature of retinal wiring rather than something specific to the midget-parvocellular pathway.

\section{Comparison of human and macaque retina}

It could be argued that much of what we have found here has been predicted by previous studies of macaque monkey retina. But it is important to remember that human and macaques have had at least 25 million years independent evolution in widely differing environments. Clear precedents of rapid evolutionary changes in retinal populations are evident, for example, on comparison of wild and domestic cat retina (Williams et al., 1993) and wolf and domestic dog retina (Peichl, 1992). In humans, it has been estimated that alleles leading to red-green color vision deficiencies in European populations have increased in prevalence from $<2 \%$ to over $8 \%$ in the past 120 generations (Post, 1982). Here, we have found that, overall, the similarities between human and macaque retina greatly outweigh the differences, supporting the value of macaque monkey as a non-human primate model for normal and abnormal visual function.

\section{References}

Abbott CJ, McBrien NA, Grünert U, Pianta MJ (2009) Relationship of the optical coherence tomography signal to underlying retinal histology in the tree shrew (Tupaia belangeri). Invest Ophthalmol Vis Sci 50:414-423.

Abramov I, Gordon J, Chan H (1991) Color appearance in the peripheral retina: effects of stimulus size. J Opt Soc Am A 8:404-414.

Ahmad KM, Klug K, Herr S, Sterling P, Schein S (2003) Cell density ratios in a foveal patch in macaque retina. Visual Neurosci 20:189-209.

Anderson SJ, Mullen KT, Hess RF (1991) Human peripheral spatial resolution for achromatic and chromatic stimuli: limits imposed by optical and retinal factors. J Physiol 442:47-64.

Blakemore C, Vital-Durand F (1986) Organization and post-natal development of the monkey's lateral geniculate nucleus. J Physiol 380:453-491.

Boycott BB, Wässle H (1991) Morphological classification of bipolar cells of the primate retina. Eur J Neurosci 3:1069-1088.

Boycott BB, Wässle H (1999) Parallel processing in the mammalian retina. The Proctor Lecture. Invest Ophthalmol Vis Sci 40:1313-1327.

Boycott BB, Hopkins JM, Sperling HG (1987) Cone connections of the horizontal cells of the rhesus monkey's retina. Proc R Soc Lond B Biol Sci 229:345-379.

Bringmann A, Syrbe S, Görner K, Kacza J, Francke M, Wiedemann P, Reichenbach A (2018) The primate fovea: structure, function and development. Prog Retin Eye Res 66:49-84.

Buzás P, Blessing EM, Szmajda BA, Martin PR (2006) Specificity of M and L cone inputs to receptive fields in the parvocellular pathway: random wiring with functional bias. J Neurosci 26:11148-11161.

Calkins DJ, Schein SJ, Tsukamoto Y, Sterling P (1994) M and L cones in macaque fovea connect to midget ganglion cells by different numbers of excitatory synapses. Nature 371:70-72.

Chan TL, Martin PR, Clunas N, Grünert U (2001) Bipolar cell diversity in the primate retina: morphologic and immunocytochemical analysis of a New World monkey, the marmoset Callithrix jacchus. J Comp Neurol 437:219-239.

Chandra AJ, Lee SCS, Grünert U (2019) Melanopsin and calbindin immunoreactivity in the inner retina of humans and marmosets. Visual Neurosci 36:E009.

Chichilnisky EJ, Kalmar RS (2002) Functional asymmetries in ON and OFF ganglion cells of primate retina. J Neurosci 22:2737-2747.

Chiquet C, Dkhissi-Benyahya O, Chounlamountri N, Szel A, Degrip WJ, Cooper HM (2002) Characterization of calbindin-positive cones in primates. Neuroscience 115:1323-1333.

Croner LJ, Kaplan E (1995) Receptive fields of P and M ganglion cells across the primate retina. Vision Res 35:7-24.

Crook JM, Lange-Malecki B, Lee BB, Valberg A (1988) Visual resolution of macaque retinal ganglion cells. J Physiol 396:205-224.
Crook JD, Peterson BB, Packer OS, Robinson FR, Troy JB, Dacey DM (2008) Y-cell receptive field and collicular projection of parasol ganglion cells in macaque monkey retina. J Neurosci 28:11277-11291.

Curcio CA, Allen KA (1990) Topography of ganglion cells in human retina. J Comp Neurol 300:5-25.

Curcio CA, Sloan KR, Kalina RE, Hendrickson AE (1990) Human photoreceptor topography. J Comp Neurol 292:497-523.

Curcio CA, Allen KA, Sloan KR, Lerea CL, Hurley JB, Klock IB, Milam AH (1991) Distribution and morphology of human cone photoreceptors stained with anti-blue opsin. J Comp Neurol 312:610-624.

Dacey DM (1993) The mosaic of midget ganglion cells in the human retina. J Neurosci 13:5334-5355.

Dacey DM, Petersen MR (1992) Dendritic field size and morphology of midget and parasol ganglion cells of the human retina. Proc Natl Acad Sci USA 89:9666-9670.

de Souza CF, Nivison-Smith L, Christie DL, Polkinghorne P, McGhee C, Kalloniatis M, Acosta ML (2016) Macromolecular markers in normal human retina and applications to human retinal disease. Exp Eye Res 150:135-148.

Drasdo N, Fowler CW (1974) Non-linear projection of the retinal image in a wide-angle schematic eye. Br J Ophthalmol 58:709-714.

Drasdo N, Millican CL, Katholi CR, Curcio CA (2007) The length of Henle fibers in the human retina and a model of ganglion receptive field density in the visual field. Vision Res 47:2901-2911.

Field GD, Gauthier JL, Sher A, Greschner M, Machado TA, Jepson LH, Shlens J, Gunning DE, Mathieson K, Dabrowski W, Paninski L, Litke AM, Chichilnisky EJ (2010) Functional connectivity in the retina at the resolution of photoreceptors. Nature 467:673-677.

Ghosh KK, Goodchild AK, Sefton AE, Martin PR (1996) Morphology of retinal ganglion cells in a New World monkey, the marmoset Callithrix jacchus. J Comp Neurol 366:76-92.

Grünert U, Martin PR (2020) Cell types and cell circuits in human and non human primate retina. Prog Retin Eye Res. Advance online publication. Retrieved Feb 5, 2020. doi: 10.1016/j.preteyeres.2020.100844.

Grünert U, Greferath U, Boycott BB, Wässle H (1993) Parasol (P $\alpha$ ) ganglion cells of the primate fovea: immunocytochemical staining with antibodies against GABAA receptors. Vision Res 33:1-14.

Grünert U, Martin PR, Wässle H (1994) Immunocytochemical analysis of bipolar cells in the macaque monkey retina. J Comp Neurol 348:607-627.

Haverkamp S, Haeseleer F, Hendrickson A (2003) A comparison of immunocytochemical markers to identify bipolar cell types in human and monkey retina. Vis Neurosci 20:589-600.

Hendrickson A (2005) Organization of the adult primate fovea. In: Macular degeneration (PenfoldPL, Provis JM, eds). Berlin, Heidelberg: Springer.

Hicks TP, Lee BB, Vidyasagar TR (1983) The responses of cells in macaque lateral geniculate nucleus to sinusoidal gratings. J Physiol 337:183-200.

Jacoby RA, Marshak DW (2000) Synaptic connections of DB3 diffuse bipolar cell axons in macaque retina. J Comp Neurol 416:19-29.

Jacoby RA, Wiechmann AF, Amara SG, Leighton BH, Marshak DW (2000) Diffuse bipolar cells provide input to OFF parasol ganglion cells in the macaque retina. J Comp Neurol 416:6-18.

Kántor O, Mezey S, Adeghate J, Naumann A, Nitschke R, Énzsöly A, Szabó A, Lukáts A, Németh J, Somogyvári Z, Völgyi B (2016) Calcium buffer proteins are specific markers of human retinal neurons. Cell Tissue Res 365:29-50.

Kaplan E, Shapley RM (1986) The primate retina contains two types of ganglion cells, with high and low contrast sensitivity. Proc Natl Acad Sci USA 83:2755-2757.

Kolb H, DeKorver L (1991) Midget ganglion cells of the parafovea of the human retina: a study by electron microscopy and serial section reconstructions. J Comp Neurol 303:617-636.

Kolb H, Marshak DW (2003) The midget pathways of the primate retina. Doc Ophthalmol 106:67-81.

Kolb H, Linberg KA, Fisher SK (1992) Neurons of the human retina: a Golgi study. J Comp Neurol 318:146-187.

Kwong JM, Caprioli J, Piri N (2010) RNA binding protein with multiple splicing: a new marker for retinal ganglion cells. Invest Ophthalmol Vis Sci 51:1052-1058.

Lee BB, Martin PR, Grünert U (2010) Retinal connectivity and primate vision. Prog Retin Eye Res 29:622-639.

Lee SCS, Martin PR, Grünert U (2019) Topography of neurons in the rod pathway of human retina. Invest Ophthalmol Vis Sci 60:2848-2859. 
Lennie P, Pokorny J, Smith VC (1993) Luminance. J Opt Soc Am A 10:12831293.

Liu Z, Kurokawa K, Zhang F, Lee JJ, Miller DT (2017) Imaging and quantifying ganglion cells and other transparent neurons in the living human retina. Proc Natl Acad Sci USA 114:12803-12808.

Luo X, Ghosh KK, Martin PR, Grünert U (1999) Analysis of two types of cone bipolar cells in the retina of a New World monkey, the marmoset, Callithrix jacchus. Visual Neurosci 16:709-719.

Marc RE, Sperling HG (1977) Chromatic organization of primate cones. Science 196:454-456.

Martin PR, Grünert U (1992) Spatial density and immunoreactivity of bipolar cells in the macaque monkey retina. J Comp Neurol 323:269-287.

Martin PR, Grünert U (1999) Analysis of the short wavelength sensitive ("blue") cone mosaic in the primate retina: a comparison of New World and Old World monkeys. J Comp Neurol 406:1-14.

Martin PR, Lee BB, White AJR, Solomon SG, Rüttiger L (2001) Chromatic sensitivity of ganglion cells in the peripheral retina. Nature 410:933-936.

Masri RA, Percival KA, Koizumi A, Martin PR, Grünert U (2016) Connectivity between the OFF bipolar type DB3a and six types of ganglion cell in the marmoset retina. J Comp Neurol 524:1839-1858.

Merigan WH, Katz LM (1990) Spatial resolution across the macaque retina. Vision Res 30:985-991.

Merigan WH, Maunsell JH (1993) How parallel are the primate visual pathways? Annu Rev Neurosci 16:369-402.

Merigan WH, Byrne CE, Maunsell JH (1991) Does primate motion perception depend on the magnocellular pathway. J Neurosci 11:3422-3429.

Milam AH, Dacey DM, Dizhoor AM (1993) Recoverin immunoreactivity in mammalian cone bipolar cells. Vis Neurosci 10:1-12.

Missotten L (1974) Estimation of the ratio of cones to neurons in the fovea of the human retina. Invest Ophthalmol Vis Sci 13:1045-1049.

Mullen KT, Beaudot WH (2002) Comparison of color and luminance vision on a global shape discrimination task. Vision Res 42:565-575.

Mullen KT, Sakurai M, Chu W (2005) Does L/M cone opponency disappear in human periphery? Perception 34:951-959.

Nassi JJ, Callaway EM (2009) Parallel processing strategies of the primate visual system. Nat Rev Neurosci 10:360-372.

Østerberg GA (1935) Topography of the layer of rods and cones in the human retina. Acta Ophthalmol (Copenh) 6:1-102.

Packer O, Hendrickson AE, Curcio CA (1989) Photoreceptor topography of the adult pigtail macaque (Macaca nemestrina). J Comp Neurol 288:165-183.

Peichl L (1992) Topography of ganglion cells in the dog and wolf retina. J Comp Neurol 324:603-620.

Peng YR, Shekhar K, Yan W, Herrmann D, Sappington A, Bryman GS, van Zyl T, Do MTH, Regev A, Sanes JR (2019) Molecular classification and comparative taxonomics of foveal and peripheral cells in primate retina. Cell 176:1222-1237.

Percival KA, Martin PR, Grünert U (2013) Organisation of koniocellularprojecting ganglion cells and diffuse bipolar cells in the primate fovea. Eur J Neurosci 37:1072-1086.

Perry VH, Cowey A (1988) The lengths of the fibres of Henle in the retina of macaque monkeys: implications for vision. Neuroscience 25:225-236.

Petrusca D, Grivich MI, Sher A, Field GD, Gauthier JL, Greschner M, Shlens J, Chichilnisky EJ, Litke AM (2007) Identification and characterization of a Y-like primate retinal ganglion cell type. J Neurosci 27:11019-11027.

Polyak SL (1941) The Retina. Chicago: The University of Chicago Press.

Post RH (1982) Population differences in red and green color vision deficiency: a review, and a query on selection relaxation. Soc Biol 29:299-315.

Provis JM, Dubis AM, Maddess T, Carroll J (2013) Adaptation of the central retina for high acuity vision: cones, the fovea and the avascular zone. Prog Retin Eye Res 35:63-81.

Puthussery T, Venkataramani S, Gayet-Primo J, Smith RG, Taylor WR (2013) NaV1.1 channels in axon initial segments of bipolar cells augment input to magnocellular visual pathways in the primate retina. J Neurosci 33:16045-16059.

Reid RC, Shapley RM (2002) Space and time maps of cone photoreceptor signals in macaque lateral geniculate nucleus. J Neurosci 22:6158-6175.

Rodieck RW, Binmoeller KF, Dineen J (1985) Parasol and midget ganglion cells of the human retina. J Comp Neurol 233:115-132.

Rodriguez AR, Pérez de Sevilla Müller L, Brecha NC (2014) The RNA binding protein RBPMS is a selective marker of ganglion cells in the mammalian retina. J Comp Neurol 522:1411-1443.
Schein SJ (1988) Anatomy of macaque fovea and spatial densities of neurons in foveal representation. J Comp Neurol 269:479-505.

Schiller PH, Logothetis NK, Charles ER (1990) Functions of the colour-opponent and broad-band channels of the visual system. Nature 343:68-70.

Shapley R, Perry VH (1986) Cat and monkey retinal ganglion cells and their visual functional roles. Trends Neurosci 9:229-235.

Shlens J, Field GD, Gauthier JL, Grivich MI, Petrusca D, Sher A, Litke AM, Chichilnisky EJ (2006) The structure of multi-neuron firing patterns in primate retina. J Neurosci 26:8254-8266.

Sinha R, Hoon M, Baudin J, Okawa H, Wong RO, Rieke F (2017) Cellular and circuit mechanisms shaping the perceptual properties of the primate fovea. Cell 168:413-426.e12.

Sjöstrand J, Olsson V, Popovic Z, Conradi N (1999) Quantitative estimations of foveal and extra-foveal retinal circuitry in humans. Vision Res 39:2987-2998.

Solomon SG, Lee BB, White AJ, Rüttiger L, Martin PR (2005) Chromatic organization of ganglion cell receptive fields in the peripheral retina. J Neurosci 25:4527-4539.

Strettoi E, Masri RA, Grünert U (2018) AII amacrine cells in the primate fovea contribute to photopic vision. Sci Rep 8:16429.

Telkes I, Lee SC, Jusuf PR, Grünert U (2008) The midget-parvocellular pathway of marmoset retina: a quantitative light microscopic study. J Comp Neurol 510:539-549.

Tong J, Phu J, Khuu SK, Yoshioka N, Choi AY, Nivison-Smith L, Marc RE, Jones BW, Pfeiffer RL, Kalloniatis M, Zangerl B (2019) Development of a spatial model of age-related change in the macular ganglion cell layer to predict function from structural changes. Am J Ophthalmol 208:166-177.

Tsukamoto Y, Omi N (2015) OFF bipolar cells in macaque retina: type-specific connectivity in the outer and inner synaptic layers. Front Neuroanat 9:122.

Tsukamoto Y, Omi N (2016) ON bipolar cells in macaque retina: type-specific synaptic connectivity with special reference to OFF counterparts. Front Neuroanat 10:104.

Vaney DI (1994) Patterns of neuronal coupling in the retina. Prog Ret Eye Res 13:301-355.

Wässle H (2004) Parallel processing in the mammalian retina. Nat Rev Neurosci 5:747-757.

Wässle H, Grünert U, Röhrenbeck J, Boycott BB (1990) Retinal ganglion cell density and cortical magnification factor in the primate. Vision Res 30:1897-1911

Wässle H, Grünert U, Martin PR, Boycott BB (1994) Immunocytochemical characterization and spatial distribution of midget bipolar cells in the macaque monkey retina. Vision Res 34:561-579.

Weltzien F, Percival KA, Martin PR, Grünert U (2015) Analysis of bipolar and amacrine populations in marmoset retina. J Comp Neurol 523:313334.

Wikler KC, Rakic P (1990) Distribution of photoreceptor subtypes in the retina of diurnal and nocturnal primates. J Neurosci 10:3390-3401.

Wikler KC, Rakic P, Bhattacharyya N, MacLeish PR (1997) Early emergence of photoreceptor mosaicism in the primate retina revealed by a novel cone-specific monoclonal antibody. J Comp Neurol 377:500-508.

Wilkinson MO, Anderson RS, Bradley A, Thibos LN (2016) Neural bandwidth of veridical perception across the visual field. J Vis 16:1-1.

Williams RW, Cavada C, Reinoso-Suárez F (1993) Rapid evolution of the visual system: a cellular assay of the retina and dorsal lateral geniculate nucleus of the Spanish wildcat and the domestic cat. J Neurosci 13:208-228.

Wool LE, Crook JD, Troy JB, Packer OS, Zaidi Q, Dacey DM (2018) Nonselective wiring accounts for red-green opponency in midget ganglion cells of the primate retina. J Neurosci 38:1520-1540.

Yan W, Peng YR, van Zyl T, Regev A, Shekhar K, Juric D, Sanes JR (2020) Cell atlas of the human fovea and peripheral retina. Sci Rep 10:9802.

Yoshioka N, Zangerl B, Nivison-Smith L, Khuu SK, Jones BW, Pfeiffer RL, Marc RE, Kalloniatis M (2017) Pattern recognition analysis of age-related retinal ganglion cell signatures in the human eye. Invest Ophthalmol Vis Sci 58:3086-3099.

Zhang H, Cuenca N, Ivanova T, Church-Kopish J, Frederick JM, MacLeish PR, Baehr W (2003) Identification and light-dependent translocation of a cone-specific antigen, cone arrestin, recognized by monoclonal antibody 7G6. Invest Ophthalmol Vis Sci 44:2858-2867. 